\title{
Narrowing the Tax Gap Through Presumptive Taxation
}

\author{
Kyle D. Logue ${ }^{*} \&$ Gustavo G. Vettori ${ }^{* *}$
}

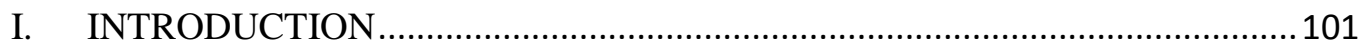

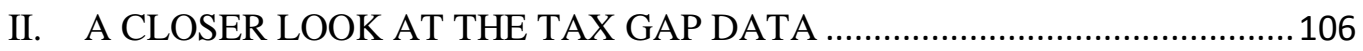

A. What the Numbers Show (and Don't Show) ..................................................106

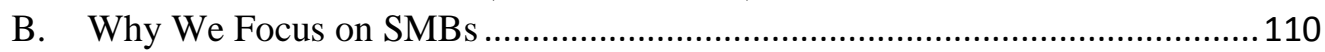

III. WHY THE SMB TAX GAP MATTERS AND WHAT TO DO ABOUT IT .111

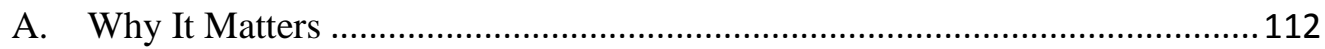

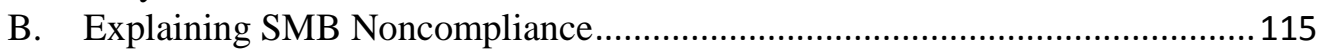

C. Obvious Potential Solutions to the SMB Tax Gap (Other than Presumptive

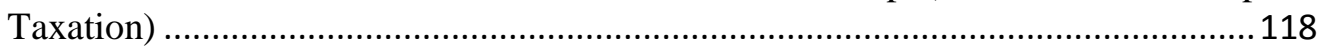

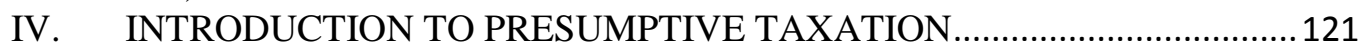

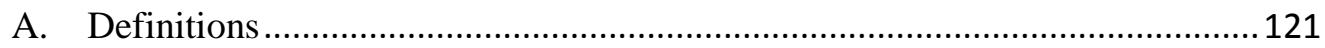

B. Examples of Presumptive Provisions in the Current U.S. Tax System.............122

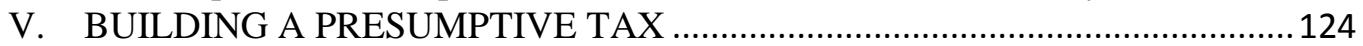

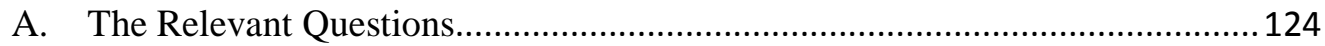

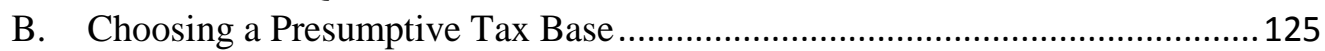

1. A Lump-Sum Business Tax ................................................................ 125

2. Pure Gross Receipts (or “Turnover”) Tax.............................................. 127

3. Modified Gross Receipts (MGR) Tax: Using Historical Line-of-Business Profit

Ratios to Estimate Net Income. ...................................................................... 129

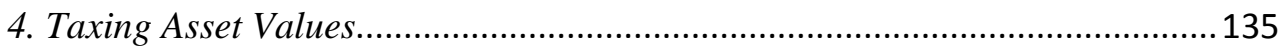

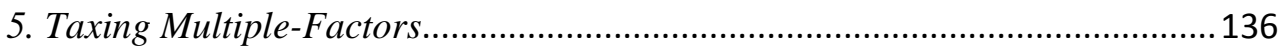

C. Of Mandatory Minimums, Optional Presumptive Regimes, and Other Variations 137

1. Mandatory Minimum ..................................................................... 137

2. The Ex-Post, Optional Presumptive Tax .................................................. 138

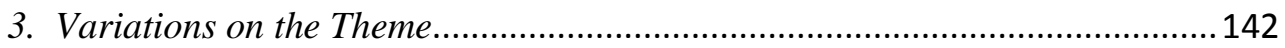

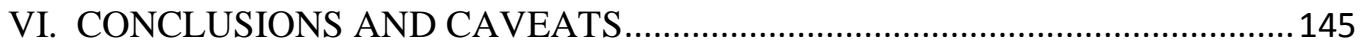

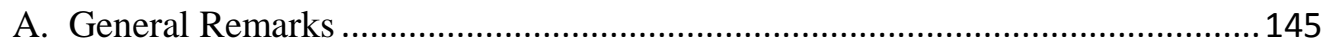

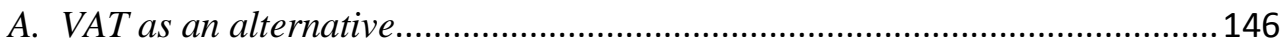

${ }_{* *}^{*}$ Wade H. McCree Jr., Collegiate Professor of Law, University of Michigan Law School.

** L.L.M., University of Michigan Law School; Doctoral Candidate, University of São Paulo. The authors wish to thank Reuven Avi-Yonah, Alex Raskolknikov, Chris Sanchirico, and Joel Slemrod as well as the participants at the 2009 Summer Tax Workshop at the University of Colorado and the fall 2009 Columbia Law School Tax Colloquium for their questions and comments. 


\section{INTRODUCTION}

Can the United States government significantly reduce the federal tax gap? This question has attracted a great deal of scholarly attention over the years and has been the focus of numerous government reports. The "tax gap" is the official term for the Treasury Department's estimate of the difference between what American taxpayers should pay to the federal government in a given tax year (that is, the amount of tax they owe, based on a reasonable interpretation of existing tax laws as applied to particular taxpayers' circumstances) and what they actually pay. ${ }^{1}$ This estimate is derived from painstaking and detailed audits of randomly selected returns and it is the best overall benchmark of taxpayer noncompliance we have. According to the most recent numbers (from the 2001 tax year), the annual U.S. tax gap is around $\$ 290$ billion. This represents a noncompliance rate of roughly $15 \%{ }^{2}$ It is fair to say, then, that U.S. taxpayers on average remit $15 \%$ less in tax to the government than they actually owe. ${ }^{3}$

That would, of course, mean a compliance rate of $85 \%$, which sounds pretty good for the sort of laws that the federal income tax laws are. If we were talking about murder or armed robbery, a compliance rate of only $85 \%$ would obviously be unacceptable. (As a conceptual matter, what would an $85 \%$ "compliance” rate in that context even mean?) But if we think of tax laws as being on a par with traffic laws or intellectual property rules (and other laws the violation of which is considered merely mala prohibitum), an 85-percent compliance rate sounds almost respectable. ${ }^{4}$ Moreover, the tax gap in the United States is probably smaller than the tax gap in most other countries, including other nations with developed economies. ${ }^{5}$ Certainly U.S. tax-

\footnotetext{
${ }^{1}$ We are using the term pay loosely here. What we really mean is remit. The party with a taxremittance obligation is the party who is required by law to write the check to the government for the amount of the tax. Tax noncompliance, therefore, is failure to remit the taxes that one owes. Tax payment is a more vague term, sometimes used to mean remittance (as in the text here) and sometimes used to mean "to bear the burden of." Joel Slemrod, Does It Matter Who Writes the Check to the Government? The Economics of Tax Remittance. 61 NAT’L TAX J. 251 (2008).

2 IRS, United States DePartment of THE TREAsury, Reducing the Federal Tax Gap: A Report on Improving Voluntary Compliance (2007), available at http://www.irs.gov/pub/irsnews/tax_gap_report_final_080207_linked.pdf. The \$290 million figure is actually the "net tax gap.” The "gross tax gap," which includes tax dollars that are remitted late or only after enforcement action by the IRS, is obviously higher. The gross tax gap for the 2001 tax year was around \$345 billion.

3 This statistic is sometimes referred to as the "net misreporting percentage" or "NMP." The NMP is the amount of income misreported divided by the sum of the absolute values of the amounts that should have been reported. TREASURY, supra note 2, at 12-13.

4 With intellectual property rules, we can at least conceive of what the numerator and denominator would be. For example, the numerator might be the total amount that users of copyrighted material actually paid (directly or indirectly) to the relevant copyright holders for the use of the copyrighted material during a given period of time and the denominator would be the total amount that should have been paid based on a reasonable interpretation of copyright law. We are guessing that copyright holders would be thrilled with a "copyright gap" of only $15 \%$.

${ }^{5}$ We say "probably" because no other country calculates the tax gap in precisely the way that the United States does. Indeed, few countries make any systematic effort to measure their tax gap at all. Sweden has done so, using a methodology very different from that of the United States, and has found an overall noncompliance rate in the neighborhood of $10 \%$. The United Kingdom has recently made efforts to measure its tax gap, and it has broken it down into direct taxes (individual and corporate income tax as well as inheritance tax), and indirect taxes (mainly the VAT). For direct taxes, the (very rough) range estimate is between 5 and 15\% (with a point estimate of around 9\%). KNOWLEDGE ANALYSIS AND INTELLIGENCE Directorate of Her Majesty's Revenue \& Customs, Estimation of Tax Gap For Direct Taxes 4 tbl. 4.1 (2005), available at http://www.hmrc.gov.uk/research/direct-tax-gaps.pdf. For indirect taxes, noncompliance is estimated to be between 12 and 16\%, depending on the year. Her MAJESTY's REVENUE
} 
compliance rates are higher than those in developing countries, which have shadow economies that are much larger, as a fraction of overall GDP, than the one in the United States. ${ }^{6}$ For all of these reasons, some commentators hold the view that the tax gap is not a serious problem. ${ }^{7}$

On the other hand, noncompliance is noncompliance. And the United States government could really use all of those unremitted tax dollars. Of course, this is always true; there never seems to be enough money to pay for all of our government programs. But the need for tax revenue will grow increasingly acute in the coming years, as the U.S. government moves from stimulus mode into debt-reduction mode and as the country's obviously unsustainable (even if temporarily necessary) fiscal path becomes impossible even for Congress and the President to ignore. ${ }^{8}$ Any serious attempt to respond to the impending debt crisis will almost certainly entail not only a cut in spending and an increase in tax rates, but also some sort of increased effort to collect tax dollars that are already owed under existing tax laws. ${ }^{9}$ Given this context, even a $15 \%$ noncompliance rate may prove to be unacceptably high.

What's more, the $15 \%$ rate of noncompliance (or "net misreporting percentage") does not fully capture the problem. If someone told you that the overall violent crime rate in the United States was roughly five reported offenses per 100 inhabitants, would this be enough information to give you a sense of the problem and how best to respond to it? Or would you also like to know that in rural areas the violent-crime rate is half the national average; and, in the large cities, it is double the national average? And in certain high-crime areas within high-crime cities, five times the national average? Obviously, these more fine-grained estimates of legal "noncompliance” would be important data points as well, as they might provide support for targeted law-enforcement efforts in the high-crime regions. In the same way, the seemingly modest $15 \%$ historical tax noncompliance figure is an aggregate average that masks smaller areas of serious abuse.

\& Customs, MeAsuring Indirect TAX LOsSES - 2007 at 5 tbl. 2.1 (2007), available at http://www.hmrc.gov.uk/pbr2007/mitl.pdf.

6 See Friedrich Schneider \& Dominik H. Enste, Shadow Economies: Size, Causes, and Consequences, 38 J. ECON. LiT. 77, 82 tbl. 2 (2000) (reporting data suggesting that the United States has one of the smallest shadow economies in the world, even among OECD countries). This point is confirmed with somewhat more recent data in Friedrich Schneider, The Size of the Shadow Economies of 145 Countries all over the World: First Results over the Period 1999 to 2003 (Inst. For Study Lab., IZA Discussion Paper No. 1431, 2004), available at http://ssrn.com/abstract=636661; and Friedrich Schneider \& Robert Klinglmair, Shadow Economies Around the World: What Do We Know? (Center for Res. Mgmt. \& Arts, CREMA Working Paper No. 2004-03, 2004), available at http://www.cremaresearch.ch/papers/2004-03.pdf. This last paper shows an $8.6 \%$ average shadow economy size in the United States for 2002/2003, while the OECD average for the same period is $16.4 \%$. Brazil, for its part, had an average of $39.8 \%$ in 1999/2000, and the Latin American countries averaged $41 \%$ in this period. African countries averaged $41 \%$ and Asian countries 26\%. Id. Another study of the Brazilian shadow economy came up with a 39.4\% estimate. Claudio Lucinda \& Paulo Arvate, A Study on the Shadow Economy and the Tax-gap: the Case of CPMF in Brazil (2005) (unpublished manuscript presented at the 5th Annual meeting of the Public Choice Society), available at http://www.thaigoodgovernance.org/upload/content/296/shadow\%20economy\%20in\%20brazil.pdf.

${ }^{7}$ IRS and the Tax Gap: Hearing Before the H. Comm. on the Budget, 110тн Cong. 109 (2007) (statement of Chris Edwards, Director of Tax Policy Studies, Cato Institute) ("I think to most people, that [compliance rate, $86 \%$ ] sounds like a pretty high number. We rarely get $100 \%$ compliance with any law”).

${ }^{8}$ Daniel N. Shaviro, TaXes, Spending, and the U.S. Government's March Towards BANKRUPTCY (2006).

${ }^{9}$ See Calvin H. Johnson, Two Years of the Shelf Project, 126 TAX Notes 513 (2010). 
For example, among the most well-studied and closely analyzed topics in the tax field is the problem of corporate tax shelters. Tax shelters are extraordinarily complex and highly aggressive (though usually not patently illegal) transactions designed entirely for the purpose of reducing, and in some cases eliminating, the tax liabilities of large corporate or wealthy individual taxpayers. For years these shelters have been a serious concern, both because of the direct loss in tax revenue associated with them and because of the indirect effect on taxpayer morale. That is, when the average small-business owner learns that a bunch of large corporations have been engaging in highly sophisticated and extremely aggressive tax-shelter activity, the sort of aggressive, avoidance-bordering-on-evasion ${ }^{10}$ transaction that is beyond the financial reach of the average taxpayer, she begins to wonder, why does the government allow this?

As bad as the problem of corporate tax shelters can be, however, it is dwarfed by the level noncompliance - often in the form of outright evasion - among small and medium-sized businesses ("SMBs"). ${ }^{11}$ By far the most serious area of tax noncompliance in the United States, and probably in every other country in the world, is that of SMBs, whether these businesses are operated as sole proprietorships, partnerships, or corporations. As we explain in greater detail below, the SMB netmisreporting percentage is the primary source of the U.S. tax gap. What is especially surprising about the SMB tax gap in the United States is how little it has been studied. In fact, with a few exceptions, SMB noncompliance has been largely ignored in the legal literature on the U.S. income tax. ${ }^{12}$ It is the aim of this Article to remedy that omission, to focus scholarly attention on the problem of SMB tax noncompliance in the United States, and to explore some new, potentially radical solutions.

To be a bit more specific, in this Article we suggest the possibility of shifting from the existing income tax regime, which currently is characterized by a large degree of noncompliance, to a system of presumptive taxation of SMB income. A presumptive tax imposes a levy on one thing as a proxy for (or rough approximation of) another thing. For example, a tax on some percentage of a business's gross receipts or its asset values rather than on a precise measure of income might be considered a rough proxy

${ }^{10}$ By tax "evasion" we mean intentional noncompliance with the tax laws: the taking of tax positions that the taxpayer knows (or should know) is clearly prohibited by law. The more general term "noncompliance," by which we mean a tax position that an objective tax expert (say, a court ruling on the position) would say is in violation of the tax laws, includes evasion but also includes lots of tax positions that are not evasion. That is, given the large degree of substantive uncertainty in the tax laws, it is often the case that taxpayers will take positions that are not clearly illegal (that are not evasion) but that, if detected and ruled on by a court, would be found to be examples of noncompliance. Thus, noncompliance includes taking tax positions that turn out, when the rules are applied correctly, to be unsupported by the law, even if this is not the taxpayer's intention. In defining the tax gap, the Treasury Department seems to be using a concept of noncompliance similar to the one just described. Of course, it is possible for taxpayers to take positions that are not clearly illegal but that have a small chance of being upheld if reviewed. For a general discussion of these different types of noncompliance, and how tax penalties should be designed to respond to them, see Kyle D. Logue, Optimal Tax Compliance and Penalties When the Law is Uncertain, 27 VA. TAX REV. 241 (2007).

${ }^{11}$ We define SMBs more precisely below.

${ }^{12}$ One important exception to this statement is Susan Cleary Morse, Stewart Karlinsky \& Joseph Bankman, Cash Business and Tax Evasion, 20 STAN. L. \& PoL'y REV. 37 (2009) (reporting on a series of interviews with noncompliant SMB taxpayers and their accountants). There has also been an excellent law review article on SMB (or self-employment) noncompliance problem in other countries. Piroska Soos, Self-Employment Evasion and Tax Withholding: A Comparative Study and Analysis of the Issues, 24 U.C. DAVIS L. REV. 107 (1991). 
for a business income tax. (And as we shall see, some countries employ some version of an SMB gross receipts tax, and some use an asset tax.) What distinguishes a presumptive income tax for the purposes of our analysis is that it attempts to tax income in a very rough way, sacrificing accuracy of measurement for a reduction of compliance and enforcement costs.

Every tax system, of course, trades off accuracy for simplicity to some degree. ${ }^{13}$ And how much of a sacrifice in accuracy is required depends on the context. The term presumptive tax has traditionally been used to describe tax regimes in environments in which administrative/enforcement costs are unusually high and therefore accuracy of income measurement is unusually expensive. Such environments are often found in developing countries, where it is necessary to make unusually large sacrifices in income-measurement accuracy in order to be able to collect any taxes at all. ${ }^{14}$ Indeed, as one commentator put it, "The main virtue of presumptive taxation is that it may be the only effective way to tax small businesses in developing countries."15

This observation may apply to developed countries as well, or so we argue. That is, given the extremely high enforcement costs associated with a tax on net business income for SMBs, this Article argues that the most efficient and distributively fair system of SMB taxation may include some form of presumptive income tax. Put differently, we suggest that when it comes to the taxation of SMB income, policymakers in developed economies should consider approaches that have been used successfully by governments in developing economies, where the SMB tax noncompliance problems are even more severe.

One type of presumptive tax that we focus on (but do not go so far as to endorse) would ground SMB tax liability on presumed profits rather than on actual profits. Under one particular version of such a system, Congress would develop (or would delegate to the Treasury Department the task of developing) a range of "presumed-profit ratios" for particular categories of businesses. These presumed profit ratios, which would be based on historical experience within those lines-of-business, would be applied to the actual reported gross receipts of SMB taxpayers. The primary benefit of such a "modified gross receipts" presumptive tax regime would be that it would dispense with the need to evaluate taxpayers' individualized (and easily overstated) business expense deductions, as business deductions would not be relevant for the definition of the tax base. This change would dramatically reduce the costs of

${ }^{13}$ For early statements by economists of the accuracy-simplicity tradeoff in the tax context, see Joel Slemrod \& Shlomo Yitzhaki, Analyzing the Standard Deduction as a Presumptive Tax, 1 INT’L TAX \& Pub. FIn. 25, 32 (1994) [hereinafter Slemorad \& Yitzhaki, Standard Deduction] ("Whether it is explicit or implicit, all tax systems must trade off the accuracy of tax-base measurement against the cost of that measurement.”); and Louis Kaplow, The Standard Deduction and Floors in the Income Tax, 50 TAx L. REV. 1, 2 (1994) ("Such limits, like the standard deduction, save compliance and administrative costs but sacrifice accurate measurement"). For a more general treatment of the point, see Louis Kaplow, How Tax Complexity and Enforcement Affect the Equity and Efficiency of the Income Tax, 49 NAT'L TAX J. 135 (1996) [hereinafter Kaplow, Complexity and Enforcement]; and Louis Kaplow, Accuracy and Complexity in the Income Tax, 14 J. L. Econ. \& ORG. 61 (1998) [hereinafter Kaplow, Accuracy].

14 E.g., Joel Slemrod \& Shlomo Yitzhaki, Tax Avoidance, Evasion, and Administration, 3 HandBook Pub. Econ. 1423, 1456 (2002) [hereinafter Slemord and Yitzhaki, Tax Avoidance] (noting that presumptive taxes "are a pervasive element in the tax systems of many developing countries"). Slemrod and Yitzhaki observe that " $[\mathrm{t}] \mathrm{his}$ kind of tax makes sense in cases where the otherwise desirable tax base is difficult for the tax authorities to measure, verify, and monitor.” Id.

15 Kenan Bulutoglu, Presumptive Taxation, in IMF Fiscal AfFairs DeP'T, Tax Policy HANDBOOK (Parthasarathi Shome ed., 1995). 
enforcement. Part of the administrative-cost savings would come from an expanded use of compulsory withholding, which would include payments to independent contractors as well as payments to other SMB taxpayers. ${ }^{16}$ The beauty of the expanded withholding option is that, by effectively making payers vicariously responsible for the tax obligations of the SMB payees, we actually get closer to the social optimum, in terms of efficiency and distribution. ${ }^{17}$

We should emphasize here that the presumptive-tax proposals discussed in this Article are directed primarily at that portion of the U.S. SMB noncompliance problem that is attributable to merchant-to-merchant transactions - where one merchant pays another merchant (the latter sometimes being called the independent contractor) for services or goods. It is with respect to those sorts of transactions that the use of presumed profit ratios combined with compulsory withholding can provide the greatest overall improvement in compliance-per-dollar-of-administrative-cost. In addition, our analysis has relevance to the optimal tax treatment of merchant-to-consumer transactions, insofar as those transactions involve credit- or debit-card purchases. For such transactions, third-party (credit-card-company) reporting to the IRS would insure that the government would have reliable information on at least a significant fraction of the SMB taxpayer gross receipts. ${ }^{18}$ With respect to cash transactions, however, there is little to gain (in terms of improved enforcement per administrative dollar spent) by imposing a presumed-profit tax on reported gross receipts. For one thing, in such settings, the merchants receiving payments from consumers often simply understate their gross receipts, which is a problem that our modified-gross-receipts tax obviously cannot easily address. Although it is not clear from the existing evidence precisely what fraction of the SMB tax underpayment problem is attributable to these very small merchant-to-consumer businesses, many tax commentators believe that it is the dominant source of the problem. We do discuss briefly how presumptive-tax principles might be used to improve compliance in such settings. Moreover, we discuss one possible solution to the problem of evasion in cash transactions that has been used in

\footnotetext{
${ }^{16}$ Kyle D. Logue \& Joel Slemrod, Of Coase, Calabresi, and Optimal Tax Liability, 63 TAx L. REV. 797 (2010).

${ }^{17}$ Our analysis is entirely consistent with, and borrows heavily from, the part of the optimal tax literature that addresses the tradeoff between accuracy and complexity. See, e.g., Nicholas Stern, Optimum Taxes with Errors in Adminstration, 17 J. PuB. ECON. 181 (1982). The Article owes a special debt to the work of Joel Slemrod and Shlomo Yitzhaki on the marginal cost of funds in general and on presumptive taxes in particular, which is cited throughout. A seminal paper on the subject of the efficiency and equity aspects of presumptive taxation is Vito Tanzi \& Milka Casanegra de Jantscher, Presumptive Taxation: Administrative, Efficiency, and Equity Aspects (IMF, Working Paper No. 87/54, 1987).

${ }^{18}$ Third-party reporting of electronic transactions has recently been adopted in the United States. The Housing and Economic Recovery Act of 2008, Pub. L. No. 110-289, 122 Stat. 2654, created 26 U.S.C. $\S 6050 W$ (2010) ("Returns Relating to Payments Made in Settlement of Payment Card and Third Party Network Transactions"), which requires credit and debit card companies and other "payment settlement entities" to file information returns with the IRS and the merchant. These returns are to include the merchant's name, address, taxpayer identification number, as well as the gross amount of the transactions the entity processed for the merchant. The provision covers not only credit and debit cards but also thirdparty payment networks such as online payment systems. Morse, Karlinsky \& Bankman, supra note 12, find that revenue from credit card transactions is reasonably well reported by small businesses (most of the interviewees in their survey said that they reported those transactions because they suspected that the IRS would know about them), while revenue from cash transactions is less well reported. What this suggests is that, in regard to credit-card transactions, if there is to be any income tax evasion, it will likely occur on the deductions side. As discussed in the text, it is deduction-side evasion that the presumptive income tax is designed to address.
} 
other countries that is not necessarily related to presumptive tax principles, but can be used in conjunction with them. ${ }^{19}$ Finally, this Article takes as given that there is a societal preference for imposing some sort of tax on business income.

Therefore, the Article is devoted to developing the idea of a presumptive business income tax alternative to the existing income tax regime that seems to be failing and the Article does not consider the possibility of simply replacing the income tax on SMBs with a VAT, which might be the best alternative. ${ }^{20}$ The Article is organized as follows. Part II provides more data on the tax gap and explains what we mean by an SMB. Part III discusses why the tax gap actually matters, putting the problem in terms of efficiency and distributive fairness (which can in turn be put in terms of the "marginal cost of funds") and explains why some of the most obvious solutions might not be the best response. Part IV introduces the idea of the presumptive tax by offering an operational definition of the concept and by identifying some aspects of the existing U.S. income tax regime that have presumptive-tax characteristics. Part $\mathrm{V}$ provides the basic framework for how to think about designing an SMB presumptive tax. In this Part we address the following questions:

- what the optimal presumptive tax base would be;

- $\quad$ whether the presumptive tax should be mandatory or optional;

- whether (if mandatory) it should be a mandatory minimum only (as with the AMT) or a mandatory maximum and minimum;

- whether (if optional) the presumptive should be accompanied by a dual-track enforcement regime (where one set of penalties applies to those who opt into the presumptive tax and another for those who do not); and

- whether, if adopting a statutory presumptive tax proves not to be a workable idea, it would make sense to make use of presumptive-tax principles as part of the IRS audit strategy for SMBs.

Part VI contains our conclusions and some caveats to our analysis.

\section{A CLOSER LOOK AT THE TAX GAP DATA}

A. What the Numbers Show (and Don't Show)

Consider the most recent data on the federal income tax gap, based on the 2001 tax year. Of the $\$ 345$ billion total gross tax gap for that year, \$285 billion is for "underreporting," which means either the understatement of receipts or overstatement of deductions, exemptions, or credits. ${ }^{21}$ The other $\$ 60$ billion of the tax gap (\$345 billion minus $\$ 285$ billion) is attributable to the nonfiling of returns ( $\$ 27$ billion) or the underpayment of taxes that the taxpayer reports as being owed ( $\$ 33$ billion). ${ }^{22}$ Of the \$285 billion attributable to underreporting (which is our primary concern here), \$197 billion is attributable to income tax returns filed by individuals, $\$ 30$ billion to income tax returns filed by corporations, $\$ 54$ billion to employment tax returns, and $\$ 4$ billion

${ }^{19}$ See infra note 113 for a discussion of a Brazilian regime that uses tax credits to encourage consumers to monitor tax reporting by SMBs.

${ }^{20}$ Below, we explain why a true VAT on SMBs would suffer from problems of its own. See infra Part VI.

${ }^{21}$ TREASURY, supra note 2, at 12.

${ }^{22} I d$. 
to estate tax returns. ${ }^{23}$ Of the $\$ 197$ billion of the tax gap attributable to individual income tax returns, $\$ 109$ billion was from individual business income, $\$ 56$ billion was from understated individual non-business income (understated wages, interest, dividends, and capital gains), and \$32 billion was attributable to overstated nonbusiness deductions or exemptions (\$15 billion) or credits (\$17 billion) ${ }^{24}$ All of this can be seen in the Treasury Department's “Tax Gap Map for the Tax Year 2001," reproduced here.

TAX GAP MAP for Tax Year 2001 (in \$ Billions)

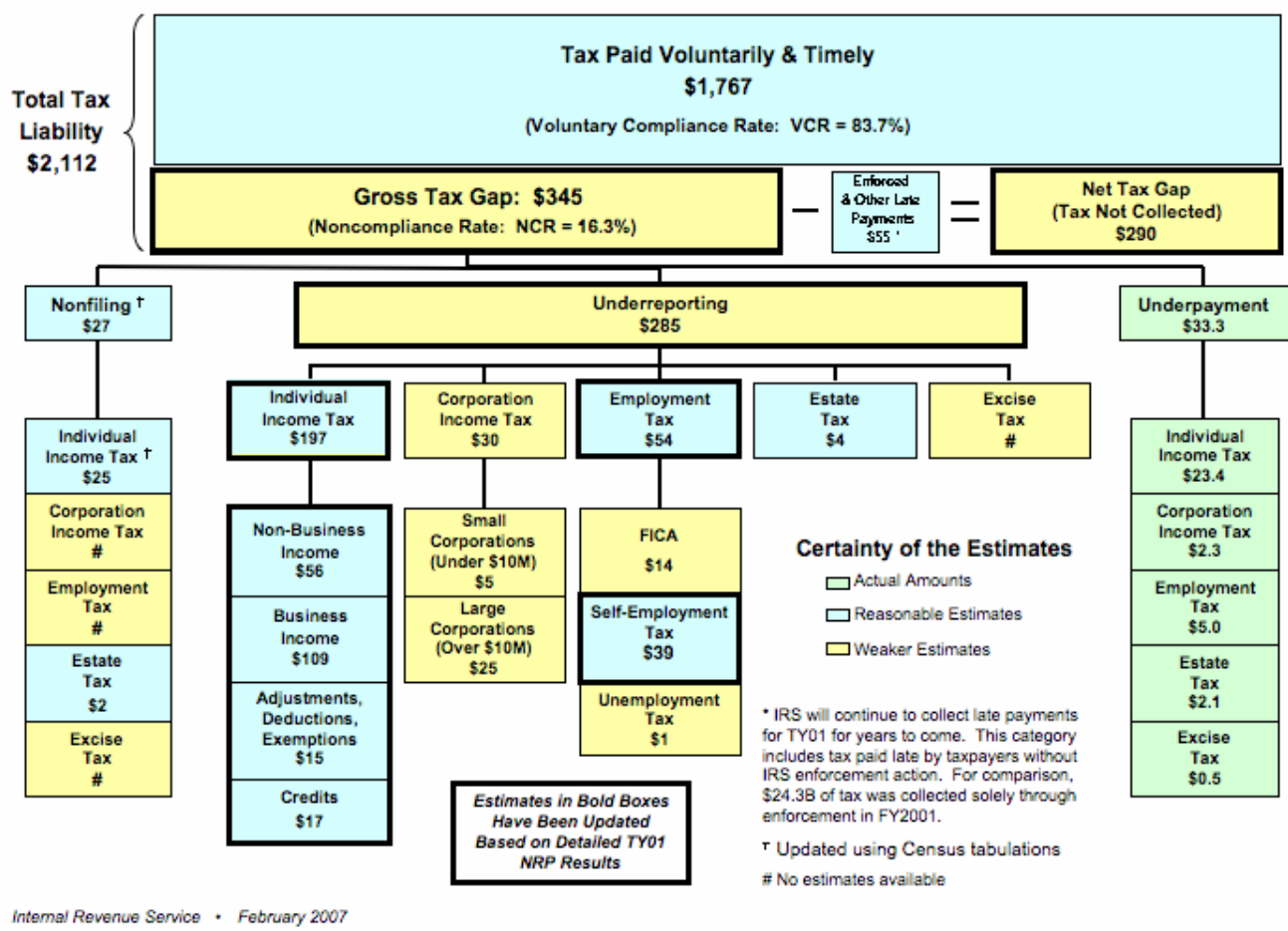

Notice that, of the $\$ 109$ billion tax gap attributable to individual business income, $\$ 68$ billion comes from "non-farm sole proprietor income" - or, SMBs operated as sole proprietorships other than farms. ${ }^{25}$ The remaining $\$ 41$ billion of individual business income underreporting tax gap is attributable to small farms (\$6 billion); rents and royalties (\$13 billion); and SMBs operated as partnerships, S-corps, or through some sort of trust (\$22 billion). ${ }^{26}$

One fact to take from all of these numbers is the disproportionate amount of the income-tax gap attributable to sole proprietors. In fact, the non-farm, sole-proprietor income-tax gap constituted $19.7 \%$ of the overall annual gross federal tax gap for 2001 . By contrast, a relatively small amount of the tax gap- roughly $16.2 \%$ of the total - was attributable to underreported non-business-related individual income, a category that,
${ }^{23} I d$.
${ }^{24}$ Id.
${ }^{25}$ Id. at 13.
${ }^{26} I d$. 
again, would include understated wages, tips, interest, and capital gain income. ${ }^{27}$ This later gap is remarkably small, relatively speaking, considering that the total number for non-business individual income is by far larger than the total amount of business income for individuals.

Another way to see the problem is to focus on the rates of noncompliance. The Treasury Department calculates an aggregate "net misreporting percentage" (or "NMP") for various categories of taxpayers by dividing the amount of the income that is misreported by the amount that should have been reported. ${ }^{28}$ And using this figure, there is a good deal of variation in noncompliance rates depending on the type of taxpayer in question. For example, the NMP for non-business individual income is only around $4 \%$ and it is less than $1 \%$ for wages. By contrast, for non-farm soleproprietor income, the NMP was calculated to be a whopping 57\%. That is, individuals who ran their own businesses as sole proprietorships in 2001 remitted, in the aggregate, only $43 \%$ of the income taxes they actually owed. ${ }^{29}$ But that was not the only problem area. The noncompliance rate for farm income was even higher $(71 \%)$, but the magnitude in revenue terms of the problem there was much smaller (with an underreporting gap of only $\$ 6$ billion). ${ }^{30}$ These misreporting percentages far exceed the noncompliance rate attributable to the corporate income tax overall, which in the aggregate was only $18.5 \%$. This estimate for corporate noncompliance, however, combines the noncompliance figures for large and small corporations, and, for reasons discussed further below, we suspect that the rate of noncompliance for the latter would be greater. ${ }^{31}$ Likewise, the noncompliance rate for the category of partnerships and SCorps was in the neighborhood of $18 \%$, but we suspect that statistic masks some pockets of serious noncompliance. ${ }^{32}$

Indeed, just as the $15 \%$ figure for overall noncompliance hides areas of much more serious noncompliance, even the more fine-grained statistics above tend to mask areas of substantial abuse. Take non-farm sole proprietors, for example. The 2001 data reveal that, although sole proprietors as a group are among the least compliant, not all sole proprietors wildly understate their business income. Although it is true that (based on the 2001 data) most sole proprietors filing Schedule C returns understated their business income to some extent, not all did. In fact, the majority of the understatement

\footnotetext{
${ }^{27} I d$.

${ }^{28} \mathrm{Id}$.

${ }^{29}$ Id.

${ }^{30}$ This is simply because farm income as a type of individual business income is small relative to other types of SMB income.

${ }^{31}$ TrEAsury, supra note 2, at 11. According to the Treasury tax gap study, small corporations (those with annual revenue of less than $\$ 10$ million) exhibited a tax gap of \$5 billion; whereas large corporations (over \$10 million in revenues) had a tax gap of \$25 billion. Id. The Treasury study did not break the corporate NMP down into these two categories, but reported an $18.5 \%$ figure for all corporations. We suspect that the noncompliance rate for small corporations is significantly higher than that for large corporations, for reasons we discuss below (including the expectation of greater IRS enforcement efforts for large corporate taxpayers, given the obvious economies of scale of doing so).

32 In other words, although the overall average rate of noncompliance for individual returns reporting income from businesses organized in the form of S corporations or partnerships was only $18 \%$, it seems likely that this results from most $\mathrm{S}$ corporations and partnerships reporting fairly accurately (with far less than $18 \%$ noncompliance) but with relatively few attempting to engage in serious noncompliance (with underreporting considerably greater than 18\%). In other words, it seems likely that most of the S corporation and partnership noncompliance is attributable to a relatively small minority of such taxpayers. Such an outcome would be consistent with what the Treasury Department has found with respect to noncompliance among sole proprietors, as discussed in the text immediately below.
} 
(around 60\%) was attributable to $10 \%$ of the Schedule C filers. ${ }^{33}$ Indeed, half of the sole proprietors that filed Schedule Cs in 2001 that were found to have understatements on their returns understated by less than $\$ 900$; whereas, the $10 \%$ who were the largest offenders understated by $\$ 6,200$ on average; and the worst $2 \%$ understated by over $\$ 20,000$ on average.

What explains this degree of unevenness in noncompliance? As we discuss further below, it may be that most sole proprietors are relatively honest or risk averse or feel bound by social norms to limit the amount of their tax underpayment; whereas, a small subset of sole proprietors are relatively dishonest or less averse to risk or do not feel bound by such norms. This unevenness in noncompliance may also be explained by the fact that some of these sole proprietors have more opportunities to evade than others. In any event, whether the cause is variation in taxpayer honesty, aversion to risk, respect for norms, or opportunities to cheat, it is this unevenness of compliance that creates the inequity (horizontal or vertical) that requires some sort of remedy, as we argue in further detail in Part III below. Given that corporations and partnerships face the same sorts of dynamics (that is, they are run by people with different degrees of honest or risk aversion and different levels of respect for norms of legal compliance,) we suspect that a similar degree of unevenness of noncompliance exists among corporations and partnerships.

One of the key insights, then, of the various studies of the U.S. tax gap is that individually owned businesses are significantly more likely to under-comply with the tax laws than are other types of businesses. ${ }^{34}$ What the studies do not reveal is precisely what those individually-owned businesses look like. Are they mostly businesses that sell directly to consumers, such as local restaurants and corner groceries? Or are they mostly independent contractors who provide services and goods to other merchants? Earlier studies broke out "informal suppliers" from the larger category of "non-farm sole proprietors," with the former being described as businesses that sold predominantly to consumers and often engaged in cash transactions. ${ }^{35}$ Unsurprisingly, that study found that the rate of noncompliance was considerably higher for the informal-supplier merchant-to-consumer group (in the neighborhood of $80 \%$ ) than it was for all other non-farm sole proprietors (closer to 30\%). ${ }^{36}$ Even that study, however, did not make clear what the relative size of the two groups was. And the more recent studies, the ones that look at the 2001 tax year data, make no effort to break down the data in this way. What that means is that we cannot be certain as to what portion of the nonfarmsole-proprietor tax gap involves the type of noncompliance this Article focuses on that of independent contractors who transact primarily with other businesses.

Some studies estimate that consumer cash payments may represent up to $20 \%$ of retail sales transactions in the United States, and most of the SMBs evasion could therefore be attributable to the underreporting of these cash receipts. ${ }^{37}$ With respect to

${ }^{33}$ U.S. Gov’t AcCountability Office, GAO-07-1014, Tax Gap: The Strategy for Reducing the Gap Should Include Options for Reducing Sole Proprietor Noncompliance, Report to the S. Finance Comm. 13-15 (2007).

${ }^{34}$ TREASURY, supra note 2.

35 IRS, United States Department of the Treasury, Federal Tax Compliance Research: Individual Income Tax Gap Estimates for 1985, 1988, and 1992, 8 Pub. 1415 (1996).

${ }^{36}$ Id.

37 Morse, Karlinsky \& Bankman, supra note 12. The authors, citing David B. Humphrey, Replacement of Cash by Cards in U.S. Consumer Payments, 56 J. ECON. \& Bus. 211, 223 (2004), show that 
cash transactions, it is likely that those seeking to evade taxes would prefer evading through the understatement of receipts rather than through the overstatement of deductions, because the former facilitates not only income tax evasion but also sales tax evasion. The use of cash also facilitates evasion by a business's employees and suppliers, which further enhances its appeal as a tax evasion "technology.”38

There is, however, data showing that the overstatement of deductions accounts for almost as large a share of the income tax gap as does the underreporting of receipts. $^{39}$ Considering the likelihood that the substantial use of cash receipts as a means of exchange is unevenly distributed across SMBs (that is, only a subset of all SMBs receive a significant fraction of their receipts in cash), it is possible to paint the following picture: on the one hand, most of the SMB taxpayers who are inclined towards noncompliance (are dishonest or risk preferring or unaffected by compliance norms) are in fact not able to understate much of their receipts because most of their receipts are not in the form of cash. Rather, they are in the form of credit or debit-card purchases or checks, which are subject to greater third-party reporting. These potential noncompliers, then, must lean more heavily on a different evasion strategy, that of overstating deductions. There are limits, however, to the extent taxpayers can overstate their deductions; at some point the number and the size of the deductions will raise red flags with the Internal Revenue Service. As a result, these SMB taxpayers end up evading less overall than they would if they could also easily understate their receipts with impunity. On the other hand, the subset of SMBs who receive most of their receipts in the form of cash can engage in massive concealment of such receipts.

These two phenomena would explain the almost equal proportion of concealed receipts and overstated deductions in the tax gap and, at the same time, the unevenness of the amount of evasion between SMB taxpayers. That is, a few SMB taxpayers evade a lot by understating cash receipts, and a lot of them evade a little by overstating their deductions. If the picture just painted is accurate, it seems that a sound plan to curb SMB evasion should deal with both understatement of receipts and overstatement of deductions. One can even argue that the latter would tend to be the more rapidly growing part of the evasion problem if credit card payments continue to replace retail cash transactions. Therefore, as we explain later, the adoption of presumptive taxes (if coupled with other audit mechanisms such as third-party reporting, withholding, and programs capable of monitor cash payments) could be a valuable tool to deal with the SMB evasion problem as a whole.

\section{B. Why We Focus on SMBs}

The other fact not revealed in the above-described data is the precise relationship between the rate of noncompliance and the "size" of the taxpayer. For reasons discussed in the next section, our hypothesis (consistent with conventional wisdom) is that noncompliance rates (especially evasion) among business taxpayers

cash use in the United States is concentrated in retail sale transactions and that, although credit and debit cards have eroded its use, cash remains an important form of payment. In 2000 cash represented $20 \%$ of consumer payments, down from 31\% in 1974, and the use of credit and debit cards rose from $13 \%$ to $27 \%$ over the same period, while check use fell from $56 \%$ to $46 \%$.

${ }^{38}$ Id. In the Morse, Karlinsky and Bankman study, the interviewees expressed a preference for cash receipts and would understate those receipts even if this would not reduce their income tax liability.

${ }^{39}$ Gov'T AcCOUnTABILITy OfFICE, supra note 33. Understatement of receipts composes 55\% of the gap, while overstatement of deductions constitutes $45 \%$. Morse, Karlinsky and Bankman recognize this fact, although their research emphasizes the evasion of cash receipts. See supra, note 12. 
will tend to be negatively correlated with size of the taxpayer, though not necessarily in any sort of continuous (or even precisely predictable) way. ${ }^{40}$ What do we mean by size here? One obvious measure would be the taxpayer's total assets. For example, the IRS has a special "small business/self-employed" enforcement division that defines small businesses as those having assets less than $\$ 10$ million. ${ }^{41}$ The choice of a $\$ 10$-million cutoff is, of course, arbitrary; lots of other cutoff points could reasonably have been used. Other measures besides total assets also could be used, such as annual revenue or annual income. The point is that large corporate taxpayers, for a number of reasons, are less likely to engage in outright tax evasion than small business taxpayers and the choice of precisely where to draw the line between is (we freely admit) fraught with uncertainty and on some level arbitrary.

So why do we focus on the SMB tax gap rather than simply on the small business tax gap? We prefer to include what we call "medium-size" businesses to emphasize the fact that the cutoff between small and large is ultimately arbitrary, to establish that many of the business taxpayers that we are concerned about may have fairly large amounts of assets or annual revenues compared with the average individual taxpayer, and to make clear that the dividing line is not necessarily the one used by the IRS to organize its various enforcement divisions. The point is to tailor a presumptive tax regime that targets those business taxpayers most likely to engage in evasion. Further, empirical research will be necessary to nail down precisely how that group of taxpayers should be defined.

\section{WHY THE SMB TAX GAP MATTERS AND WHAT TO DO ABOUT IT}

${ }^{40}$ Giampolo Arachi \& Alessandro Santoro, Tax Enforcement for SMEs: Lessons from the Italian Experience?, 5 EJOURNAL OF TAX RES., Dec. 2007, at 225, available at http://www.atax.unsw.edu.au/ejtr/content/issues/previous/paper3_v5n2.pdf, shows that a firm's size affects tax enforcement policy in two different ways. First, the costs and returns of auditing depend on the firm size (i.e., there are economies of scale in concentrating audits in large firms that account for a large share of the tax revenues). This issue will be explored in more detail below. Second, there can be a relationship between the propensity to evade and firm size. Slemrod, for example, notes that closely held small businesses have different motivations for evasion choices than those of public corporations. While small businesses tend to follow the rationale applicable to individuals (see Part III below for the economic analysis on evasion), public corporations should be considered risk-neutral and the analysis should be focused on other kind of stimuli towards evasion (such as principal-agent relationship between managers and shareholders). Thus, the compliance analysis of SMBs and public corporations would differ and the level of evasion of each of these groups would depend on how they interact with the tax and enforcement systems. See Joel Slemrod, The Economics of Corporate Tax Selfishness (Nat'l Bureau of Econ. Research, Working Paper No. 918, 2004). Cowell proposes a model of firm compliance by which evasion would depend on concealment costs (assuming risk-neutrality in all cases). The costs of concealment would increase depending on certain variables, such as the nature of the product (products more visible on the market are harder to conceal), the size and organizational structure of the firm ("firms with a more complex organization are likely to have higher concealment costs: the more people you bring into the plot the greater the security problem you face and the greater the risk of discovery") and the role of reputation (the more important the brand name, the higher the concealment costs in virtue of the risk of brand defamation in case of engagement in illegal activities). This would indicate a negative relationship between firm size and evasion (i.e., the smaller the firm, the lower the costs of concealment and the higher the level of evasion). See Frank A. Cowell, Sticks and Carrots 17 (Toyota Int'l Ctrs. for Econ. \& Related Disciplines, Discussion Paper No. 68, 2003).

${ }^{41}$ Not surprisingly, among the top "strategic priorities" listed for this division is addressing the tax gap. See IRS, Small Business/Self-Employed Division At-a-Glance, http://www.irs.gov/irs/article/0,,id=101001,00.html (last updated Aug. 19, 2010). 


\section{A. Why It Matters ${ }^{42}$}

Before we delve too deeply into potential solutions to the SMB tax gap, we should first clearly understand why it is a problem. Indeed, if noncompliance opportunities were allocated uniformly across all taxpayers, it is not obvious that noncompliance would be a concern. That is, if the overall 15\% tax gap meant that everyone simply paid exactly $15 \%$ less than they ostensibly owed under the Code, it would be similar to an implicit reduction in tax rates. Thus, if the federal statutory effective tax rate were, say, $20 \%$ overall (including all federal taxes and all taxpayers), then, assuming a universal and uniform noncompliance rate of $15 \%$, the actual effective tax rate would be closer to $17 \%$. And that might be acceptable. ${ }^{43}$ However, if an overall effective rate of $17 \%$ were insufficient to generate the level of revenue needed to pay for the desired amount of government spending, policymakers could then simply raise statutory rates until the actual effective rate produced the desired target level of funding. ${ }^{44}$

But again, as discussed in the previous section, that is not what the actual tax gap looks like. Many taxpayers are highly compliant. Recall that wage earners tend to pay almost $100 \%$ of the taxes they owe on those wages. And again, the highest degree of noncompliance among is SMBs or the self-employed (at 57\%). ${ }^{45}$ What's more, even among the self-employed, there must be a wide divergence of compliance behavior. That is, there must be some self-employed individuals who feel compelled by personal morality, extreme risk aversion, fear of informal social sanctions, or whatever to comply with the tax laws; and they do. These discrepancies, which are to some extent reflected in the evidence discussed above, produce both unfairness and inefficiency.

To see this point, consider a simple example. Say there is a self-employed individual, Jim, who has a small consulting business that produces $\$ 100,000$ of net income, but who knows he can get away with paying very little of what he owes (for reasons having to do with the absence of withholding, little third-party reporting, and the like, which we will discuss further below). In addition, Jim feels neither personal guilt nor fear of informal social sanctions when paying as little as he can get away with. So Jim pays nothing. Joan, however, is a wage earner who makes $\$ 100,000$ as her only source of income. She pays her whole income tax liability, entirely through withholding. Finally, there is Jack, who has a small consulting business just like Jim's that produces $\$ 100,000$ net of expenses. Jack could also get away with paying no tax, for the same reasons as Jim, but he feels morally obligated to pay his full income-tax liability, and if he makes any errors, they are as likely to be overstatements as understatements of income.

The disparity between Jim and his law-abiding counterparts is obviously unfair. It is one reason why we enforce the tax laws and impose penalties for noncompliance. We have a tax system that is supposed to tax people roughly according to their ability to

42 This section borrows heavily from Joel Slemrod \& Jon BAKIJA, TAXING Ourselves: A Citizen’s Guide to the Debate Over TAXes (MIT Press 4th ed. 2008).

${ }^{43}$ Such a uniform implicit "rebate" of $15 \%$ of every taxpayer's statutory tax liability would of course have its own distributional consequences. It would be equivalent to a tax credit of $15 \%$ of each taxpayer's tax liability, an amount that would obviously increase as the taxpayer's statutory tax liability increases.

${ }^{44}$ As we discuss further below, increasing the statutory rates may increase the tax gap percentage, a fact that would have to be taken into account in setting the statutory rates as well.

${ }^{45}$ And then there are the farmers, at 72\% noncompliance. TREASURY, supra note 2, at 13. 
pay. That is why so much of the tax law is devoted to defining the income tax base accurately - to make sure that individuals of equal net income pay equal tax. (Indeed, that is why we have an income tax rather than, say, a head tax). And when this does not happen, when the goal of accurate measurement of income and assignment of tax liability is not achieved, it matters. Some would call this a problem of horizontal inequity: not taxing taxpayers of similar ability to pay a similar amount. ${ }^{46}$ Others would say that it is a problem of vertical equity. ${ }^{47}$ Either way, it is a real concern, one that we are apparently willing to spend real resources to eliminate, or at least to reduce.

In the example involving Jim and Joan, the distributive unfairness is clear. The comparison is between two individuals: one who earns his living as a self-employed small business owner, the other who works for wages. And the SMB tax gap produces precisely this type of distributive unfairness. Moreover, in such situations, the distributional consequences of noncompliance and of various responses to noncompliance are easier to identify. This is because it is generally assumed that the economic burden of an income tax lies predominantly on the income earner. The same should be true, all else equal, if the income in question were earned by a self-employed individual. Thus, improving compliance by self-employed individuals should produce an unambiguous improvement in distributional equity, albeit at some cost of enforcement. Not all SMBs, however, are self-employed individuals. Some of them are firms that have multiple owners and multiple employees and even multiple customers. In those cases, the distributional effect of improved compliance is more difficult to determine due a question of tax incidence. That is, if a noncompliant SMB with multiple owners and multiple employees and multiple customers is forced to pay more in tax, on whom will the burden of increased compliance ultimately fall - the owners, the employees, or the customers? The answer is not clear. Nevertheless, an argument could be made that, if we know nothing of the specific ability to pay of any of the relevant parties, it is better from a distributional perspective to shift a portion of the tax burden from the currently compliant taxpayers (including the owners, employees, and customers of the compliant firms) to the owners, employees, and customers of the presently noncompliant firms. ${ }^{48}$

In addition to the distributional problems just discussed, unevenly distributed noncompliance opportunities also produce allocative inefficiency, which may ameliorate some of the distributive inequities just described. Once it becomes clear that

${ }^{46}$ Joel Slemrod \& Shlomo Yitzhaki, The Costs of Taxation and the Marginal Efficiency Costs of Funds, 43 IMF STAFF PAPERS 172, 191-92 (1996) [hereinafter Slemrod and Yitzhaki, The Costs of Taxation] (discussing the social welfare implications associated with the horizontal equity created by noncompliance).

13.

${ }^{47}$ See Kaplow, Complexity and Enforcement, supra note 13; and Kaplow, Accuracy, supra note

48 Of course, if it could be shown that the owners, employees, or customers of noncompliant SMBs tend to be poorer on average than those of compliant firms (or that the Jims of the world tend to be poorer than the Jack's of the world), then the analysis might be different. Indeed, in such a case, we might think of the current SMB noncompliance problem as a nicely tailored welfare program or low-income subsidy. We are not aware of any evidence, however, suggesting that this is the case. Moreover, it seems that a welfare program of this sort should be explicit in the law, in a structured and straightforward manner, instead of hidden under non-compliance figures. It seems only fair to assume, when talking about curbing evasion, that the tax law did its job correctly when distributing the tax burden, considering all the possible shifts in incidence (of course, this is a utopia, but one has to recognize that assuming otherwise would lead to chaos). Thus, the goal of full compliance would be to achieve the distribution tailored by the tax law; if such distribution is not perfect, it should not be altered by evasion, but by a change in the law itself. 
there are types of jobs or forms of organization that are largely free from federal income taxation (if one is willing to flout compliance norms), then we should expect some changes in the supply of labor and capital. People and resources will tend to move into the areas of the economy and forms of organization with respect to which noncompliance is easiest and thus taxes are lowest, ${ }^{49}$ which in some cases will affect supply and pre-tax prices in the usual way: that is, parties in those sectors will receive lower pre-tax profits than can be found in the non-tax-favored sectors, a change that will undercut the unfairness inherent in the post-tax differences in return. What this means, however, is that, unless one can argue that SMBs produce some sort of beneficial externality to the economy (more on this argument below), there would be too many resources being devoted to these areas of the economy or forms of organization in this picture.

Of course, it is well understood that there are natural limits to this process of inefficiency crowding out inequity. For one thing, some taxpayers will be too honest or risk-averse to take advantage of the potential noncompliance subsidy if they would only switch from being a wage earner to being a small business owner. In addition, for workers who can easily characterize themselves as either employees or independent contractors, it is not clear that such a shift would affect pre-tax prices in those sectors. And if that is the case, we would be left with the massive inequity as between compliant taxpayers (either wage earners or honest SMBs) and the dishonest SMBs.

This whole fairness/efficiency argument can be put in terms of the public finance economists' preferred framework for evaluating incremental tax policy changes - the so-called Marginal Cost of Funds (MCF). The basic idea of MCF is simple: assuming the need to raise an additional $\$ 1$ in taxes, policymakers should identify the marginal social cost of raising that $\$ 1$ through marginal changes in alternative tax instruments. And then they should choose the one that has the lowest MCF. ${ }^{50}$ MCF analysis takes into account both efficiency costs (referred to as the Marginal Efficiency Cost of Funds, or MECF) and distributional consequences (sometimes denoted DC). ${ }^{51}$ To see how this works, consider how we might compare the MCF of two different responses to a $\$ 1$ loss of revenue due to taxpayer noncompliance. One policy response would be to increase the frequency and thoroughness of audits. The other would simply be to replace the lost revenue with a rate increase. Raising rates would be inexpensive (relative to increased/enhanced audits) in terms of additional administrative costs, but it would increase the "leakage" of revenue due to the distorting effect of higher marginal tax rates. ${ }^{52}$ Also, a rate increase would produce a negative distributional consequence,

49 Arachi \& Santoro, supra note 40, at 228 (citing Simon C. Parker, Does Tax Evasion Affect Occupational Choice?, 65 OxFORD Bull. ECON. \& STAT. 379 (2003)), show that "when workers can switch freely between two occupations [i.e. wage earners and self-employment] their preference for selfemployment would depend on the discretion that self-employed workers have in declaring their incomes as opposed to the relative lack of discretion by employees who are subject to withdrawal taxes and third party reporting."

${ }^{50}$ For the optimal policy, the MCF for all policy instruments would be equal. In the real world, the best that can probably be done is to figure out which instrument entails the lowest MCF at any given point and, at the margin, use that one. Slemrod \& Yitzshaki, Tax Avoidance, supra note 14.

${ }^{51}$ Thus, the MCF for tax instrument $i$ can be written as follows: $M C F_{i}=D C_{i} \times M E C F_{i}$, where $M E C F_{i}$ is the Marginal Efficiency Cost of Funds, and DC is the distributional component.

52 The MECF formula that includes administrative, compliance, and excess burden is $M E C F i=$ $\left[\gamma\left(X_{i}-M R_{i}\right)+C_{i}+M R i\right] /\left[M R_{i}-A_{i}\right]$, where $X_{i}$ is the amount of tax that would be collected in the absence of any change in behavior, $M R_{i}$ is the marginal revenue actually collected (after distortions), $X_{i}-M_{i}$ is the "leakage" due to the distortions, $\gamma$ is the social value of the utility the taxpayer is sacrificing at the margin in 
as the horizontal inequity between compliant and noncompliant taxpayers would increase. By contrast, spending more on tax enforcement (say, funding more numerous and more thorough audits) would dramatically increase administrative costs, which in turn would increase the MECF of that policy response. Such an approach would have ambiguous effects on the leakage of revenue, since increased/enhanced audits would, on the one hand, reduce evasion but, on the other hand, cause greater substitution from work to leisure. ${ }^{53}$

Spending more on tax enforcement, however, would have an unambiguously positive, i.e., cost-reducing, effect on the distributional component of the MCF. ${ }^{54}$ This last point is the intuition mentioned above, which can be restated as follows: there are social welfare costs (resulting from socially undesirable inequities) associated with requiring or allowing similarly situated taxpayers to pay different amounts of tax, and this is especially so when the party paying less is doing so through noncompliance with the rules. And hence there is social value to eliminating this inequity. ${ }^{55}$ Indeed, if society values equity along this particular dimension highly enough (or, put the other way, if we are sufficiently offended by the inequity associated with non-uniform noncompliance), then the case for increasing the enforcement budget (and perhaps reducing tax rates, keeping overall tax revenues the same) becomes stronger.

\section{B. Explaining SMB Noncompliance}

The next question is why so many SMB taxpayers exhibit such comparatively high rates of noncompliance. According to standard deterrence theory, this is no mystery. On this view, taxpayers are rational actors whose decisions regarding legal compliance depend entirely on the likelihood and magnitude of formal legal penalties. Accordingly, the answer to the tax noncompliance question is simple: people pay their taxes to avoid being punished by the government, in the form of fines or imprisonment; and if that punishment is not sufficiently probable or large, tax evasion will be the result. $^{56}$ When taxpayers are deciding whether to understate their income or not (or whether or not to file a return), they simply compare the tax savings attributable to

order to save a dollar of taxes, $C_{i}$ is the marginal private compliance cost associated with the $i$ instrument, $A_{i}$ is the marginal administrative cost, and $M R_{i}-A_{i}$ is the net revenue collected at the margin, after the administrative cost of collection. Slemrod \& Yitzhaki, Tax Avoidance, supra note 14.

${ }^{53}$ If the government increases its auditing efforts of labor income, it would have the effect, much like raising tax rates on labor income, of raising the price to taxpayers of producing labor income (which is subject to taxation) relative to the price of producing non-labor income or leisure (which is not taxed). This change in relative prices causes substitution away from the taxed activity, which is generally considered allocatively inefficient.

${ }^{54}$ This is true even if it turns out that most non-compliers have relatively low incomes. That is to say, if we assume that the tax policymakers have chosen a statutory tax rate that achieves optimal distribution under conditions of full compliance, then any improvement in compliance would by definition be an improvement in the DC number in the MCF formula. Put differently, if the optimal distribution of tax burdens calls for low-income earners to pay some taxes, then social welfare is enhanced when those taxpayers actually pay their taxes - even though they are low-income individuals. This is not to say, of course, that the improvement in the distributional component will outweigh the costs of enforcement (or the distortion in behavior) associated with the improved compliance. Indeed, that is one of the main implications of the MCF analysis.

${ }^{55}$ Kaplow, Accuracy, supra note 13.

56 See, e.g., Michael G. Allingham \& Agnar Sandmo, Income Tax Evasion: A Theoretical Analysis, 1 J. Pub. ECON. 323 (1972); and Shlomo Yitzhaki, A Note on Income Tax Evasion: A Theoretical Analysis, 3 J. Pub. Econ. 201 (1974). This tax enforcement literature, of course, was based in part on the pioneering work by Gary Becker on criminal law enforcement. See Gary S. Becker, Crime and Punishment - An Economic Approach, 76 J. PoL. ECON. 169 (1968). 
evasion with the expected costs of the potential legal sanction, which is the product of the magnitude of the fine and the probability of detection. Relative risk aversion plays a role, too, as the taking of an aggressive or clearly illegal tax position is akin to rolling the dice; hence the phrase "playing the audit lottery." The more averse one is to this sort of risk, the less appealing the noncompliance gamble will be.

On this view, the degree of SMB noncompliance should simply be a function of the lack of enforcement. And one could argue that such a conclusion is largely consistent with the evidence. Recall that the compliance rate for taxes on wages, which are subject to compulsory withholding and third-party reporting, is trivially less than $100 \%$. In contrast, the compliance rate is much lower when there is neither withholding nor third-party reporting. ${ }^{57}$ And the best explanation for the difference is pure deterrence theory. That is, when there is third-party reporting of payments made to taxpayers, there is an increase in the probability that noncompliance (at least noncompliance in the form of understated receipts) will be found out, as the IRS can cross-check information returns submitted by the payers with the tax returns of the payees and investigate discrepancies. This means an increase in the expected legal penalty for those who fail to report payments. ${ }^{58}$

In addition, compulsory withholding drastically lowers the costs of enforcement, by collecting the tax dollars from parties (for example, large corporate remitters) who, because of their size, are relatively easy enforcement targets for the taxing authority. Enforcement against large corporate taxpayers is easier in part because they are much less likely to be judgment proof than the more numerous and much smaller individual payees. That is, they are more likely to be able to pay when the tax bill comes due. ${ }^{59}$ In addition, there are economies of scale in tax enforcement. That is, there are certain fixed costs that must be incurred by the tax authority with each audit conducted on a given taxpayer (whether it is an individual or a corporation), which cost can be more economically spread over a larger revenue base with larger corporate taxpayers. $^{60}$

${ }^{57}$ See TREASURY, supra note 2, at 15 . Without such mechanisms to improve the likelihood of detection without the necessity of prior audits, SMB auditing becomes unlikely. Audits in large businesses are justifiable because of the presence of economies of scale: large businesses are smaller in number and at the same time have a large tax bill, making it worthwhile to spend money auditing them. On the other hand, SMBs are much larger in number and, individually, have a very low tax bill, making it costineffective to audit them. Thus, unless other means of enforcement and detection are used, the enforcement rate (i.e., probability of getting caught) on SMBs will be low and they will remain a "hard-to-tax" group that accounts for a large share of the tax gap.

${ }^{58}$ Numerous studies attribute the compliance-gap difference between SMB income and wage income to the existence of third-party monitors. See, e.g., TREASURY supra note 2.

${ }^{59}$ A version of the judgment-proof story has been used to explain wage withholding for income and employment taxes. As one prominent tax expert put it, "[W]ithout a pay-as-you-earn system making the employer a 'deputy tax collector,' it would be difficult, if not impossible, to collect taxes from employees who spend their wages as fast as they are received." BORIS BITTKER \& LAWRENCE LOKKEN, Federal Income Taxation of Income, Estates \& Gifts 9 111.5.2 (quoting McGraw-Hill, Inc. v. United States, 623 F.2d 700 (Ct. Cl. 1980)). The same might be said of many small businesses: because there is no withholding from payments made to SMBs, collection of the tax at the payee level may be impossible because of judgment-proof concerns. For a fuller discussion of this argument, see Logue \& Slemrod, supra note 16.

${ }^{60}$ In addition, larger corporate taxpayers are more likely to be required by non-tax regulators, or perhaps by financial markets, to maintain various records for non-tax regulatory purposes. This will further reduce the administrative costs of tax law enforcement against such large corporate taxpayers. It is also true, of course, that there are economies of scale to tax avoidance, as larger taxpayers can spread the high 
Given this deterrence-based explanation for the divergence in compliance rates, with the worst noncompliance coming from SMBs, who are not subject to any sort of withholding regime and extremely expensive to audit en masse, the obvious question is why not simply (a) impose a withholding regime and/or (b) jack up the penalties until the desired level of compliance is reached. We will discuss both of those options in due course. Some combination of those two approaches, together with a more focused audit strategy (discussed later in the article), is likely to be a part of any optimal solution. But the analysis is more complex than suggested by this picture of purely self-interested individuals constrained only by the threat of formal legal penalties.

The degree of compliance with the tax laws that we see in the United States, even among SMB taxpayers, is probably greater than such a simplified deterrence model would predict and this is true notwithstanding the serious noncompliance problem to which this Article is addressed. Many taxpayers who currently pay taxes could probably evade with almost no legal consequence, owing to low probabilities of detection and low penalties. As poor as SMB compliance currently is, in other words, it could be worse, given the very low likelihood of detection. Recall the discussion in the previous section of the compliance variation among sole proprietors: a minority of selfemployed individuals and small sole-proprietors have relatively high rates of noncompliance (whereas probably a high percentage of SMBs under-comply at least a little). So why do the other SMBs not understate their incomes by even more? So why is SMB noncompliance not worse than it is?

There are a number of possible explanations, all of which we have alluded to in the preceding discussion. For one thing, maybe SMB taxpayers overestimate the risk of detection, or perhaps they are highly risk averse. On the other hand, it seems likely that there are forces that constrain self-interested behavior other than the threat of formal legal penalties. People obviously care not only about the possibility of formal legal penalties but also about many other things: they care about what others think of them as well as what others are getting away with. They care about being treated fairly, about not being the only sucker paying his taxes, and about how their tax dollars are being spent. ${ }^{61}$ They sometimes even care about obeying the law just because it is the law. And they sometimes comply with the law not out of respect for it (or fear of it) but out of pure habit. Indeed, if it were not for some of these "softer" factors (factors other than the threat of formal penalties), the SMB tax gap might be even larger than it is. ${ }^{62}$

This broadened deterrence analysis is made more complicated by the fact that formal legal sanctions and informal nonlegal factors affecting human behavior can have complex causal relationships with each other. For example, legal sanctions and nonlegal sanctions can act as complements. When we criminalize some conduct that was previously legal, for example, the change in the formal legal rule will often create a complementary informal sanction against violating the new legal rule, at least within

cost of sophisticated tax planning over a larger tax base. Outright evasion, however, seems to move in the opposite direction: the larger the taxpaying entity, the more parties there are who must keep secret the fact of evasion, and the more difficult it is to avoid being caught. See generally, Morse, Karlinsky \& Bankman, supra note 12 (describing how use of cash-only evasion schemes tends to be limited to very small, often family-only businesses). This is a version of Cowell's concealment costs argument. See Cowell, supra note 40 .

${ }^{61}$ Slemrod \& Bakija, supra note 42.

62 James Andreoni, Brian Erard \& Jonathan Feinstein, Tax Compliance, 36 J. ECON. LiT. 818, 822

(1998). 
communities in which law abidance is highly valued. ${ }^{63}$ Alternatively, legal and nonlegal sanctions can also operate as substitutes. For example, when the introduction of a new formal legal sanction for a given activity (such as a fine for being late to pick up one's child from daycare) has the effect of "crowding out" or substituting for existing social sanctions against the same activity. ${ }^{64}$

As a result, tax policymakers should ask whether increased formal fines will improve SMB taxpayer compliance or undermine it. For example, if fines for noncompliance were already set very high, then raising them further might simply alienate taxpayers and weaken existing norms in favor of law abidance. (As discussed further below, however, we doubt that this describes the current situation with SMB taxpayers). Policymakers should also consider whether efforts to increase informal social sanctions for noncompliance might also be helpful, such as a public relations campaign to encourage tax compliance ${ }^{65}$ or perhaps occasional public shaming for the most egregious (or most notorious) examples of evasion. Would such efforts be effective or counterproductive? Although definitive answers to any these questions are difficult to come by, no drastic policy changes should be made until there are at least some educated guesses.

\section{Obvious Potential Solutions to the SMB Tax Gap (Other than Presumptive Taxation)}

Given all of these considerations, especially the cost associated with a massive increase in auditing of SMBs, one obvious potential (and possibly low-cost) solution to the SMB tax gap would be to enact compulsory income-tax withholding for business-

${ }^{63}$ Eric A. Posner, Law and Social Norms: The Case of Tax Compliance, 86 VA. L. REV. 1781 (2002).

${ }^{64}$ Uri Gneezy \& Aldo Rustichini, A Fine Is a Price, 29 J. Legal STUd. 1, 3 (2000).

65 The results of the "Minnesota Experiment" provide interesting data on this subject. See Joel Slemrod, Marsha Blumenthal \& Charles Christian, The Determinants of Income Tax Compliance: Evidence from a Controlled Experiment in Minnesota (Nat'l Bureau of Econ. Research, Working Paper No. 6575, 1998). The experiment involved five different groups of Minnesota taxpayers. One group was offered enhanced taxpayer assistance. Another received a redesigned Minnesota income tax return. Two additional large groups received "educational” letters from the Commissioner of Revenue that appealed to their sense of equity or appealed to social norms of compliance. Finally, a fifth group was informed by the Commissioner that the returns they were about to file, both state and federal, would be "closely examined." The most interesting results from the experiment lie with the groups that received the letters with audit threats and with moral reminders. Low- and medium-income taxpayers responded positively to the audit threats, reporting higher incomes in the following year. Within these groups, high-evasion-opportunity taxpayers (those with small business income or farm income) responded with a higher average change in the reported income than low-evasion-opportunity taxpayers. High-income taxpayers, however, did not respond in the same fashion. Some of them reported even less tax after receiving the audit letter. Slemrod, Blumenthal, and Christian give two plausible explanations for the behavior of high-income taxpayers. First, it is possible that such taxpayers, after receiving the letter, consulted advisors who then uncovered legitimate ways for the taxpayers to reduce their tax liability. Second, some high-income taxpayers may have perceived the audit process as a sort of negotiation in which their reported tax liability is merely their initial "bid." As for the two groups that received educational letters, one received a letter that was intended to appeal to the taxpayer's intrinsic sense of moral duty and the other received a letter that emphasized social norms. As it turned out, the first letter had little effect on compliance, whereas the second letter led to some improvement in some cases. Stephen Coleman, The Minnesota Income Tax Compliance Experiment: State Tax Results (Munich Personal RePEC Archive, Working Paper No. 4827, 2007), available at http://mpra.ub.uni-muenchen.de/4827/. The Department of Revenue of Minnesota did a follow-up experiment with this second letter confirming this result. Stephen Coleman, The Minnesota Income Tax Compliance Experiment: Replication of the Social Norms Experiment (2007), available at http://ssrn.com/abstract=1393292. 
to-business payments. Under current U.S. law, businesses are required to withhold income taxes from wage payments to their employees, but they are not required to withhold on payments to independent contractors or to corporations, even small corporations. ${ }^{66}$ We might simply expand these withholding obligations to include payments to all SMBs and the amounts withheld would be credited against the payeetaxpayer's ultimate tax liability when the payee-taxpayer filled her/its own tax return. The problem with such proposals, however, is that they largely ignore the key difference between wage payments to employees and payments to SMBs: business deductions. Most employees have relatively few deductible business expenses - at least, business expenses that do not involve third-party oversight, as is the case with reimbursed employee business expenses. Therefore, the amount of income taxes withheld from their wages ends up coming close to approximating their ultimate income tax liability. ${ }^{67}$ This is not true with SMBs, which often have many business expenses. Indeed, as the evidence discussed in the previous section makes clear, overstated deductions are a large part of the SMB tax gap.

If we were to adopt a regime of withholding for business payments to SMBs (whether the payees are independent contractors, smallish corporations, or partnerships) and we were to stay with the existing income tax regime, there would likely be some reduction in the overall tax gap, as the amount of understated gross receipts would drop. Withholding requirements are obviously a reasonable, albeit incomplete, response to the problem of understated gross receipts. ${ }^{68}$ Another useful tool to curb the understatement of receipts from consumer-to-business transactions would be third-party reporting, such as those from credit-card companies. ${ }^{69}$ This improvement, however, would likely be offset to some extent by an accompanying increase in the amount or degree of overstated business deductions by SMBs. And this increase in overstated deductions would be very difficult (that is, costly) for the IRS to police for the same reasons already discussed. Again, this is not to suggest that expanded withholding and thirdparty reporting should not be considered a part of the eventual solution to the SMB tax gap. Indeed, below we suggest exactly that. Rather, the point is that it may not be as beneficial overall (from a MCF perspective) as coupling such an expansion of compulsory withholding with a switch to a presumptive tax regime for SMBs.

${ }^{66}$ There are information reporting requirements for such payments, however.

${ }^{67}$ This is not always true, of course. Some wage earners have other businesses on the side, and for those businesses the problem of overstated deductions would be present. Also, in those cases, withholding on wages would not be expected to approximate overall taxable income, and the problem of overstated deductions again would be present. However, one should note that the cause of the overstated deductions, in this case, would be the fact that the wage-earner also runs an SMB, which is the core problem dealt with in this Article. Moreover, many wage earners actually over-withhold, which means they end up filing for a refund.

${ }^{68}$ Of course, even compulsory withholding will not solve all of the compliance problems in this context, as there will continue to be incentives for payers and payees to cooperate in the effort to evade paying taxes, since the gains from evasion can be shared between the parties. See Logue \& Slemrod, supra note 16, at 50 (showing how the market allocates the gains from tax evasion between parties to the transactions with respect to which the evasion takes place); and Morse, Karlinsky \& Bankman, supra note 12, at 58-59 (confirming through interviews that this sort of bargaining to evade taxes occurs in practice). And this problem of coordinated evasion to avoid withholding requirements would also be present with a presumptive tax regime.

${ }^{69}$ Below we discuss one possible approach to reducing the understatement of cash receipts from SMB/consumer transactions. 
Another obvious, possible low-cost response to excessive SMB noncompliance would be simply to raise the penalties. In the law-and-economics literature on deterrence, if some behavior is clearly undesirable from a social welfare perspective, the standard solution is to raise the penalties until that behavior is deterred. ${ }^{70}$ Thus, optimal deterrence on this view can be achieved by a prohibition of the anti-social conduct accompanied by a very large sanction, and the size of the penalty (the cost it should impose on the wrongdoer) should be inversely related to the probability of detection. Furthermore, the larger the sanction is, the smaller the probability of detection - that is, the amount spent on catching people - needs to be, which reduces the administrative costs of the system.

Actually imposing much larger penalties for tax evasion (including perhaps criminal penalties) may, however, have unintended consequences. Here, the interaction between the formal legal sanction and informal nonlegal sanctions would be important. For example, policymakers would need to ask whether increasing the formal penalty for tax noncompliance would have a complementary or substitutive effect on non-legal social sanctions for such behavior. The answer probably depends on how severe the new penalty is: if taxpayers perceive that tax penalties are being set too high without any reasonable correspondence to the magnitude of the law violation (but rather, say, purely with reference to the probability of detection), it is possible that compliance norms could be eroded. A modest increase in criminal penalties, however, would not likely have such counterproductive effects and might even enhance compliance norms. This might especially be likely if the increase in penalties is targeted at groups of taxpayers who have voluntarily opted to subject themselves to a regime of increased penalties. ${ }^{71}$

In sum, it seems likely that at least modest increases in formal monetary penalties and formal nonmonetary penalties (i.e., prison sentences), and imposing those penalties a little more often, could improve SMB tax compliance. These solutions, however, have their own problems and alone may not be sufficient. An increased use of jail time might mean higher overall administrative costs, both because of the costs of prison beds but also because of the increased costs of providing due process to a larger number of taxpayers. Moreover, jail time costs society in terms of the lost liberty and productivity of the criminals. (Of course, if the increased criminal fines are effective, there would also be a reduction in administrative costs insofar as there would be less noncompliance to deal with). Increasing monetary fines might, for these reasons, be a better way to go, but there are limits to how much fines can be raised as well. First, the deterrence function of fines is limited by the assets of the noncompliant taxpayers. This is a version of the judgment-proof problem mentioned above. Second, as with prison sentences, there will be political resistance to large fines based on probabilities of detection rather than purely on the magnitude of the offense for which the fines are imposed. Third, increasing penalties alone has the problem of giving taxpayers additional incentives to spend resources on avoiding those penalties, expenditures which are pure deadweight loss. ${ }^{72}$

${ }^{70}$ Becker, supra note 56, at 191.

${ }^{71}$ Alex Raskolnikov, Revealing Choices: Using Taxpayer Choice to Target Tax Enforcement, 109 Colum. L. ReV. 689 (2009). We discuss more on this possibility in Part IV below.

${ }^{72}$ See Chris Sanchirico, Detection Avoidance, 81 N.Y.U. L. REV. 1331, 1337 (2006). 
Ultimately, we will suggest a reform that incorporates some aspects of both of these ideas - expanded withholding and higher penalties for noncompliance. But we will suggest that this should be done in combination with a shift to some sort of presumptive tax regime for small and medium-sized businesses.

\section{INTRODUCTION TO PRESUMPTIVE TAXATION}

A. Definitions

Before we address the pros and cons of any particular presumptive tax solution to the SMB tax gap, we should first be clear on what we mean by the concept generally. A number of definitions have been suggested. For example, Victor Thuronyi has said that a presumptive tax "involves the use of indirect means to ascertain tax liability, which differ from the usual rules based on the taxpayer's accounts." ${ }^{\text {,3 }}$ Thus, Thuronyi emphasizes that a key aspect of any presumptive tax is that it is not based entirely on the taxpayer's records, which are subject to manipulation and abuse. Joel Slemrod and Shlomo Yitzhaki define a presumptive tax involving "tax bases, or indicators, that can serve as proxies for ideal tax bases but which are less easily manipulated and more easily monitored than the otherwise ideal tax base."74 This definition emphasizes the extent to which a presumptive tax, when designed properly, should approximate the ideal target tax, but at a lower administrative/enforcement cost.

To get a better sense of the idea, take one example. Imagine that policymakers have decided that the ideal tax base is something like "ability to pay." ${ }^{75}$ Such a tax base would satisfy society's distributional preferences or values (if we think that those with greater ability to pay taxes should be expected to pay more in taxes) and it would have efficiency advantages (if we think that ability is an innate quality that cannot be altered or manipulated). However, because directly measuring ability is administratively costly (or impossible), the best alternative might be to impose a tax on some proxy for ability, such as annual income. And indeed, a tax on income could be, and often is, thought of as a presumptive tax on ability to pay. But the story doesn't end there. Even if we have decided to tax income instead of ability directly, the task of measuring and monitoring some idealized notion of income will also present an administrative nightmare. This is why any real-world income tax base will necessarily

${ }^{73}$ Victor Thuronyi, Presumptive Taxation, in 1 TAX LAW DESIGN AND DRAFTING 401 (Victor Thuronyi ed., 1996). Bird and Zolt contend that a presumptive tax generally is characterized by an "administrative" or "involuntary" assessment. Richard M. Bird \& Eric M. Zolt, Redistribution via Taxation: The Limited Role of the Personal Income Tax in Developing Countries, 52 U.C.L.A. L. REV. 1627, 1685 (2005).

${ }^{74}$ Slemrod \& Yitzhaki, Costs of Taxation, supra note 46, at 192; see also Shlomo Yitzhaki, Cost Benefit Analysis of Presumptive Taxation, 63 FinanzArchiv: Pub. Fin. Analysis 311, 312 (2007) [hereinafter Yitzhaki, Cost Benefit Analysis] ("In other words, presumptive taxation exists whenever the legislator is using one tax base in order to approximate another tax base.”). In some ways, then, the presumptive tax idea is a repacking of the concept of "tagging," first introduced in George Akerlof, The Economics of "Tagging" as Applied to the Optimal Income Tax, Welfare Programs, and Manpower Planning, 68 AM. ECON. REV. 8 (1978).

${ }^{75}$ Note that ability to pay may in turn be a proxy for something deeper, like well-being or potential well-being or some other fundamental criterion by which human flourishing can be measured and compared. 
be only a rough approximation of whatever idealized definition of income serves as the base's benchmark. $^{76}$

As Slemrod and Yitzhaki note, "all taxes are presumptive, to some degree."77 True enough. Nevertheless, our focus will be somewhat narrower than "all taxes." We will be looking at real-world regimes that both are intended to be proxies for an income tax and are expressly designed to sacrifice accuracy of measurement to achieve substantially better compliance or lower enforcement costs or both. Before we get to these examples, however, it is important to emphasize that the more closely a presumptive tax base approximates the ideal target tax base, the closer the approximation will be to the idealized distributional consequences of that target tax base and the more equitable (whether horizontally or vertically) the tax system will be. ${ }^{78}$ Also, insofar as the presumptive tax uses a proxy for income that is less manipulable (and generally less subject to change) than the ideal definition of income, the presumptive tax actually produces an efficiency advantage over the ideal base. Put differently, a good presumptive tax should have some lump-sum element to it. ${ }^{79}$ And, of course, a good presumptive tax should entail significantly lower administrative costs than does the underlying ideal base. ${ }^{80}$ We will return to all of these points below.

\section{B. Examples of Presumptive Provisions in the Current U.S. Tax System}

It is possible to find examples of presumptive tax provisions, in the sense in which we are now using the term, within the current U.S. income tax system. For example, consider the standard deduction. The U.S. system allows individual taxpayers to choose between reducing their adjusted gross income by the sum of their actual itemized deductions or by the amount of the so-called standard deduction, which is a predetermined lump sum amount that varies only according to the taxpayer's filing status. $^{81}$ It is generally thought that the presence of itemized deductions improves the accuracy of measurement of taxpayers' ability to pay and thus improves the horizontal and vertical equity of the system (for example, by providing deductions for large uninsured medical expenses or casualty losses), such increased accuracy and fairness

${ }^{76}$ It is possible to conceive of the Haig-Simons definition of income as the theoretical benchmark for the U.S. individual income tax. See, e.g., JonAthan Gruber, Public FinANCE AND Public Policy 498 (2005) ("The benchmark that public finance economists use for defining income is the Haig-Simons comprehensive income definition, which defines taxable resources as the change in an individual's power to consume during the year.") (emphasis in original). The notion that the Haig-Simons definition of income represents the benchmark against which the existing federal income tax should be judged underlies the concept of the "tax expenditure budget." See, e.g., StAFF OF Joint Comm. On TAXATIOn, 110th Cong., A RECONSIDERATION OF TAX EXPENDITURE ANALYSIS 19 (Comm. Print 2008) available at http://www.jct.gov/x-37-08.pdf. Some critics of tax expenditure analysis have famously disagreed that the Haig-Simons definition should be the theoretical benchmark against which the federal income tax should be analyzed. See, e.g., Boris I. Bittker, Accounting for Federal "Tax Subsidies" in the National Budget, 22 NAT'L TAX J. 244 (1969).

${ }^{77}$ Slemrod and Yitzhaki, Tax Avoidance, supra note 14, at 1457 ("The conceptually pure tax base - be it the flow of income, wealth, sales revenue, or something else - cannot be perfectly measured, and the tax authority is constrained to rely on some correlate of the concept”).

${ }^{78}$ And the smaller will be the negative distributional consequences (the DC variable) in the MCF analysis.

${ }^{79}$ In MCF terms, the $X_{i}-M R_{i}$ term in the numerator of the MECF formula should be smaller under a good presumptive/proxy tax than under the ideal. That is, there should be less leakage, whether from substitution effects or evasion.

${ }^{80}$ The $A_{i}$ term in the denominator of MECF should be smaller, increasing the amount of revenue available to spending on public goods.

${ }^{81}$ I.R.C. § 63(b) (2010). 
come at the price of increased compliance and administrative costs. (Think of the taxpayers' costs of maintaining records to support such deductions and of the necessary IRS enforcement expenditures to ensure the validity of such deductions). Thus, the much simpler and, in a sense, less accurate standard deduction can be understood as a rough (and administratively cheap) approximation of the more finetuned itemized deductions. ${ }^{82}$

Another example of a presumptive tax element in the U.S. system is the alternative minimum tax ("AMT"). The AMT is a parallel tax system that runs alongside the normal income tax, with the basic difference being that the AMT disallows certain deductions, exemptions, and credits that are available under the normal tax and the AMT applies a flatter rate structure than does the normal tax. Taxpayers are required each year to figure out both their normal and AMT tax liability (called their "tentative tax liability") and remit whichever amount is larger. On the assumption that most of the deductions made available under the normal tax were put there to provide greater accuracy in terms of measuring ability to pay, then, the AMT with its lower enforcement and compliance costs - might be viewed as a type of presumptive tax. ${ }^{83}$

In both of these examples, the standard deduction and the AMT, notice that the Code is using a rough proxy for ability to pay - indeed, an even rougher proxy than is taxable income under the normal income tax rules. That is the idea: to sacrifice some accuracy in measurement for administrative savings and improved enforcement.

The reader can probably rattle off a list of other presumptive-tax elements in the Internal Revenue Code. Depreciation deductions, for example, which are fixed in the Code (to reduce compliance and administrative costs) and bear no precise relationship to actual changes in the value of business assets, have the flavor of a presumptive device. Even the 50\% limitation on deductions for business meals can be viewed this way, on the theory that the limitation roughly approximates the average non-business element of even business-related meals and, though less accurate, is cheaper than doing an individualized analysis of every case to sort out the personal components from the business components. ${ }^{84}$ And so on.

Moreover, presumptive tax elements can be found not only in the Internal Revenue Code; they have also been incorporated into the enforcement practices of the

${ }^{82}$ Indeed, this is precisely how Slemrod and Yitzhaki analyzed the standard deduction. Slemrod \& Yitzhaki, Standard Deduction, supra note 13. As we explain more fully below, the standard deduction would be an example of an ex-post optional presumptive tax, or alternative maximum tax. As it turns out, the standard deduction is a very imprecise proxy for itemized deductions. To see this point, note that the standard deduction for individuals is in the neighborhood of \$5,000 and for married couples filing jointly, $\$ 10,000$. However, the average total itemized deduction taken by individual filers who itemize is around $\$ 18,000$ and the average total itemized deduction taken by married joint-filers is around $\$ 29,000$. See Roberton Williams, Tax Policy Center, Income TaX Issues: How Do the Standard and Itemized DEDUCTIONS COMPARE? $82 \quad$ (2008), http://www.taxpolicycenter.org/briefingbook/TPC_briefingbook_full.pdf. Of course, for many (indeed most) individual taxpayers, their itemized deductions are less than the standard deduction. Indeed, that is why roughly $56 \%$ of individual taxpayers opt for the standard deduction. Id.

${ }^{83}$ That is, the AMT itself has lower administrative and compliance costs than does the normal tax. One serious problem with the AMT is that the administrative and compliance costs it creates must be incurred in addition to the administrative and compliance costs of the normal income tax. As we discuss below, this is a problem generally with mandatory minimum presumptive tax regimes, of which the AMT is one example.

${ }^{84}$ I.R.C. § 274(n) (2010). 
IRS. For example, so-called advanced pricing agreements result in a type of presumptive taxation of multinational corporations. ${ }^{85}$ Under such agreements, the IRS and the taxpayer contractually agree to a particular approach to transfer-pricing and those transfer-pricing agreements, by all accounts, only roughly approximate the multinational corporation's actual income. Another example of presumptive taxation through enforcement policy would be when tax administrators make use of proxies to determine a taxpayer's income when the taxpayer has no records to support her reported deductions. In such a case, the IRS is allowed to "reconstruct" the taxpayer's income using other sources of data, including information from the Bureau of Labor Statistics or the IRS's own surveys of individuals or firms in comparable businesses. ${ }^{86}$ Even the way in which the U.S. system enforces the tax on tipping can be seen as a presumptive tax of sorts. That is, for large restaurant employers, the amount that must be reported to the IRS on W2 forms as tip income paid to wait staff is based on a fixed percentage ( $8 \%$, to be precise) of the restaurant's gross receipts, although employeetaxpayers can attempt to justify a lower amount of tax ex post if they can prove their tips were less than that presumed amount. ${ }^{87}$

The following section examines the different possible designs of a presumptive tax and highlights the key issues policymakers must consider in choosing among them. The point of the discussion is to identify the key structural choices that must be made in setting up such a system and to examine how those choices affect the overall efficiency and distributional consequences of the tax regime.

\section{BUILDING A PRESUMPTIVE TAX ${ }^{88}$}

\section{A. The Relevant Questions}

Of course, it is controversial what the ideal business tax base is. But if we take as given the apparent preference for taxing business income in the United States, then the ideal target for an SMB tax is a tax on net income. (It is, after all, the income tax gap that is motivating this analysis ${ }^{89}$ ). Given that assumption, the next question is how best to structure a presumptive tax that aims to approximate such an ideal regime. And that question can be broken into a series of sub-questions.

- What should the SMB presumptive tax base be?

- Would the new presumptive tax regime be mandatory or optional?

${ }^{85}$ Transfer pricing methods themselves, or at least some of the methods, can also be viewed as presumptive provisions. Although some methods, such as the Comparable Unrelated Prices (CUP) method, aim at getting as close as possible to the arm's length standard and, thus, to an ability-to-pay income tax base, other methods, such as the formulary apportionment (still not accepted by the OECD and not used by the IRS, but currently used by the State of California), intentionally depart from the arm's length standard, seeking lower administrative and compliance costs.

${ }^{86}$ In the case of individual taxpayers, the IRS will generally bear the burden of proving the taxpayer's "reconstructed" tax liability insofar as that reconstruction is based on "statistical information on unrelated taxpayers.” I.R.C. § 7491(b) (2010). The Service interprets the quoted phrase as not applying to the Service's own surveys of comparable taxpayers. I.R.S. Field Serv. Adv. 200140078 (Oct. 5, 2001).

${ }^{87}$ See, e.g., I.R.C. § 6053 (2010). The presumption in this case also operates to invert the burden of proof, which is a common characteristic of legal presumptions in general, but not necessarily of presumptive tax systems.

${ }^{88}$ The basic structure of this section borrows heavily from Thuronyi, supra note 73; and Yitzhaki, Cost Benefit Analysis, supra note 74.

${ }^{89}$ Part VI of this Article will deal with the option of a VAT instead of a presumptive income tax. 
- If the presumptive tax is to be mandatory, would it be a mandatory minimum tax only or is it both a minimum and maximum (or "exclusive") tax?

- If the presumptive tax is to be optional (which of course makes it a maximum tax only), at what point would the taxpayer be required to make the election to be taxed under the presumptive regime rather than under the normal tax: at the beginning of the taxable period or at the end?

- Would the presumptive tax regime be a formal part of statutory law (as with the AMT or the standard deduction), or would it instead be part of the government's informal, nonstatutory tax-enforcement practices?

All of these related questions are taken up below.

\section{B. Choosing a Presumptive Tax Base}

The first question is what to tax. In designing a presumptive SMB tax, policymakers should select some observable factor or combination of factors that could be used to determine how much each SMB taxpayer must remit to the government. Again, the object is to choose a base that is easier to monitor and less manipulable than reported income but that sacrifices as little as possible the other main objectives of the tax system - distributional equity or fairness and efficiency. In the design of the presumptive SMB tax base, policymakers would have to compare the new tax base to the income tax base in terms of the overall effect on incentives. The income tax, for example, is known for its distortive effects on taxpayers' work/leisure decisions. Would the presumptive tax be equally distortive of those decisions? More so? Less so? Would the presumptive tax entail other distortions not associated with the income tax? In answering these questions, it is critical that the proposed presumptive tax not be judged against an ideal (fully complied with) SMB income tax, but instead should be judged against the actual SMB income tax as it works in the real world.

In the section that follows, we discuss a number of potential presumptive tax bases. For now, we limit the discussion to presumptive taxes that are both mandatory (non-optional) and exclusive (both maximums and minimums). In the subsequent sections we consider how the analysis of these presumptive tax bases would change if the regime were merely a mandatory minimum or maximum, or if it were made optional.

\section{A Lump-Sum Business Tax}

We begin with the simplest presumptive business-tax option one could imagine: a lump-sum tax on all businesses. ${ }^{90}$ The government's only enforcement task would be to make sure that each business taxpayer actually remitted the fixed amount of presumptive tax it owed. Such a tax would be akin to a federal, business licensing fee, where the only requirement to receive a business license would be the payment of

90 Thuronyi, supra note 73, at III.D.3 mentions the possibility of a slightly more refined lumpsum tax that divides taxpayers within a given industry into classes based on turnover, with a fixed tax within each band. Taxpayers could also be divided into categories based on the type and amount of capital equipment used in the business. The more distinctions made between the taxpayers to apply a lump-sum presumptive tax in different amounts, the more such tax starts looking like a Multiple-Factors presumptive tax, which will be analyzed below. 
the annual fee. ${ }^{91}$ The primary benefit of such a tax would be the relatively low administrative costs.

There would also be some efficiency advantages, efficiency advantages similar to, but not precisely the same as, those associated with a lump-sum tax on individuals. Under a head tax, every individual pays the same fixed amount of tax regardless of what she earns, indeed, regardless of any choice the taxpayer makes, other than the choice to leave the taxing jurisdiction. As a result, a head tax is utterly neutral with respect to the work/leisure choice. A lump-sum business tax would be different. Only individuals who undertake a business would have to pay the tax. Thus, it would be distortive for those taxpayers who happen to be on the fence between deciding whether or not to start a new business. (We are assuming, of course, that the lump-sum business tax would not tax leisure). A lump-sum, presumptive tax, then, has the effect of erecting a barrier to entry for small or unprofitable companies, just as any fixed business cost might act as a barrier to entry. For those individuals who have already made the decision to start a business and paid the fixed tax/fee (that is, those for whom the lump sum tax is now a sunk cost), subsequent decisions (regarding work, leisure, or whatever) would be largely unaffected; at that point, the lump-sum business tax would have the efficiency properties of a head tax.

The main problem with a pure, lump-sum business tax is the distributional consequence. Any lump-sum tax is highly regressive, assuming there is a range of incomes (or as economists would say, heterogeneity) among taxpayers. The fixed levy would obviously constitute a smaller percentage of income as for high-income or highprofit taxpayers than it would for low-profit (or no-profit) businesses. And some businesses would be pushed out of the market entirely simply because they would have no means to pay the levy. This is another way of stating the barrier-to-entry point mentioned above, which is both an efficiency and a fairness concern.

Because of these distributional and efficiency concerns, a pure lump-sum business tax of any substantial size is almost certainly out of the question. A lumpsum business tax large enough to fully replace the income tax on SMBs would be a nonstarter. Nevertheless, a small, lump-sum SMB tax, if it were accompanied by a commensurate reduction in federal income tax rates on business income (or if it were made creditable against an outstanding income tax liability), is at least a plausible policy response to the SMB noncompliance problem and could conceivably be welfare enhancing. That is, it could, by allowing income tax rates to be lowered, reduce the labor/leisure distortion and thereby the marginal cost of funds. And those efficiency gains might outweigh the distributive costs mentioned above. Moreover, there could be some ancillary administrative benefits to the creation of a new comprehensive federal SMB licensing fee. Such a program might make simpler the task of tracking small businesses that receive payments mostly in cash and often stay entirely off the federal tax roles, a problem that will bedevil even most presumptive tax regimes. However, if we can afford the cost of hiring an army of IRS agents to fan out across the countryside to check for valid federal SMB business licenses, that would suggest a more direct solution to the SMB tax gap than this article is proposing - simply

91 The tax could be limited only to SMBs and not applied to larger businesses, but it is not clear what the advantage of that limitation would be. Larger business taxpayers, of course, would pay both the lump-sum tax and their regular income tax, which could be somewhat lower because of the existence of the lump-sum tax. 
increasing the audit budget. In any event, as mentioned, such a fee would not be a significant response to the current large and persistent SMB income tax gap. Although such taxes have been used in some developing countries where the problem of noncompliance is considerably greater even than in the United States, the amounts have (unsurprisingly) been quite small. ${ }^{92}$

\section{2. $\quad$ Pure Gross Receipts (or “Turnover”) Tax}

Another possible presumptive tax, which has the potential to reduce administrative costs dramatically, would be a tax on SMBs' gross receipts. ${ }^{93}$ Imagine replacing the existing income tax on those businesses that qualify as SMBs with a tax on all revenue received by those businesses during the relevant period with no deductions for business expenses. Recall that a large part of the SMB income tax gap is attributable to overstated deductions. Therefore, the main advantage of a gross receipts or turnover tax would be to eliminate the need for the taxing authority to monitor and verify SMB taxpayers' deductions as well as to eliminate the taxpayers' need to keep track of their expenses for tax purposes. If such a tax were adopted, it could be administered through a new compulsory withholding regime for payments to SMBs, thus minimizing the problem of understated gross receipts.

There are, of course, well known distributional and efficiency problems with a gross receipts tax, problems that would ultimately disqualify such a tax (in its purest form) as a serious solution to the SMB income tax gap in the United States. The flaws are easy to spot. On the distributional side, a business taxpayer's gross revenues cannot be expected even remotely to approximate that taxpayer's ability to pay, except by sheer accident. Thus, if individual A's small business brings in revenue of $\$ 100,000$ but also produces business-related expenses of $\$ 100,000$, individual $A$ is, from the ability-to-pay perspective, no better off than individual B who spends the year lounging on the beach and earns no income. ${ }^{94}$ Thus, a regime that forced A to pay a hefty tax while allowing B to pay nothing would be wildly unfair. Or consider individual C, who has the same gross revenue as A for the year $(\$ 100,000)$ but who has essentially no business expenses. Few would disagree that it would be unfair, or distributively unjust, to impose on $\mathrm{A}$, who has no net income, the same tax that we impose on $\mathrm{C}$, who has a net income of $\$ 100,000$. But that is exactly what a pure gross receipts tax would do. It is possible that behavioral changes in response to a pure mandatory gross receipts tax might eliminate some of this distributive unfairness, as investment would shift away from businesses that have high expenses to businesses with relatively low expenses, but it seems likely that the distributional consequence would not be fully eliminated.

${ }^{92}$ Pakistan enacted something like this in 1991. The Pakistani version was a fixed tax on small businesses, including small shopkeepers, traders, and various other professionals. The tax provided for a fixed charge for all businesses, with the only differentiation being between businesses in rural and urban areas. The point of the tax was explicitly to respond to the government's inability, at reasonable expense, to reach these small-business taxpayers through the normal modes of taxation. But the amount of the tax was small. Ahmad Kahn, Presumptive Tax as Alternate Income Tax Base: A Case Study of Pakistan, 32 PAK. DEv. REV. 991, 997, 1000 (1993); see also Thuronyi, supra note 73.

${ }^{93}$ Vito Tanzi and Milka Casanegra de Jantscher notice that some francophone African countries that originally had a lump-sum presumptive tax have replaced it with a presumptive tax on gross receipts. Tanzi \& Casanegra de Jantscher, supra note 17, at 10-11. The same authors also report that Colombia, in 1983, established a general presumption of net income based on gross receipts. Id. at 11.

${ }^{94}$ Individual A would, in fact, be worse off, from a work/leisure perspective. 
On the efficiency side, a gross receipts tax is a disaster. First, a gross receipts tax would distort all sorts of business decisions, discouraging efficient investments in high-expense but high-profit fields and inducing cost-cutting measures that actually lower pre-tax profits. To see these points, consider investor $\mathrm{D}$, who is trying to decide between investing in either of two businesses: business X, which produces $\$ 200,000$ in gross receipts and $\$ 100,000$ in expenses and business $\mathrm{Y}$, which produces gross receipts of $\$ 100,000$ but zero business expenses. Each business is assumed to be maximizing the profit available to that business. In a world without taxation, or in a world with an ideal income tax regime that is fully enforced, D would be indifferent as between the two investments, since both options would produce the same net after-tax return. And that is the efficient result; assuming a competitive market, societal wealth is maximized when firms seek to maximize profits, not when they seek solely to minimize costs. Under a pure, gross receipts tax, however, there would be an incentive to minimize costs even when doing so might not maximize overall profits. Thus, in the case above, under a gross receipts tax, business $\mathrm{Y}$ would be strongly preferred to business $\mathrm{X}$, even though in a taxless world, investor $\mathrm{D}$ would be indifferent as between the two.

One might be tempted to conclude that a gross receipts tax at least has the efficiency advantage of encouraging cost cutting, since under such a regime a business can generate additional tax-free income simply by cutting expenses and holding revenue constant. The problem with that suggestion, however, is that a gross receipts tax can encourage cost-cutting that is not profit maximizing from a pre-tax perspective. For example, imagine a taxpayer who is maximizing available profit within her business such that if she reduced her business expenses by $\$ 1$ she would lose, say, $\$ 1.10$ in revenue. ${ }^{95}$ In the absence of taxes, or even under an income tax, she would not do such a thing, as it would reduce her profit. Under a gross receipts tax, however, she might. For example, if the gross receipts tax rate were $12 \%$, such a cut would be after-tax worthwhile, though a pre-tax loss. ${ }^{96}$ In fact, so long as the gross receipts rate is greater than the marginal profit on the last dollar spent on business expenses, the taxpayer would maximize her after-tax profit by continuing to cut costs even though such cost-cutting reduces her pre-tax profits. Obviously, a gross receipts tax in this situation would induce inefficient cost cutting. ${ }^{97}$

Another distortion associated with a gross receipts tax is the so-called "cascading" effect. A particular tax is said to cascade when it ends up being imposed at every level of production with no offset or credit for taxes paid at prior levels. Thus, under a cascading tax, two businesses that are identical in all respects except for the degree of vertical integration will be taxed very differently, as the more vertically integrated firm will pay a lower gross receipts tax than the less vertically integrated firm, since the gross receipts tax is imposed only on transactions between firms and never on transactions within firms. This leads to purely tax-induced vertical integration of firms within particular industries; and it is obviously inefficient (unless one has a theory for why there should be a tax-induced vertical integration of firms).

${ }^{95}$ And if she increased her business expenses by another $\$ 1$, she would generate, say, only $\$ 0.90$ in additional revenue. Thus, the business is currently maximizing profits.

${ }^{96}$ She would save $\$ 0.12$ from the reduction in taxes, which is greater than the additional $\$ 0.10$ return on the $\$ 1$ investment she had been getting.

${ }^{97}$ Of course, if a taxpayer could cut business expenses without losing any pre-tax revenue (say, when cutting $\$ 1$ produces a $\$ 0.90$ loss of revenue), she would have an incentive to do that even without a gross receipts tax. 
What's more, neither an income tax nor a consumption tax, at least in their ideal forms, would have this cascading effect, as those taxes (assuming full compliance) are generally neutral with respect to the vertical integration of the firm. ${ }^{98}$

And finally, a gross receipts tax produces much the same labor-leisure distortion that an income or consumption tax does. Thus, if a taxpayer can choose between working another hour and producing taxable gross receipts, on the one hand, or engaging in untaxed leisure, on the other, there will be a tax inducement toward the latter.

The distributional and efficiency problems associated with a pure gross receipts tax seem disqualifying. However, it should be kept in mind that the relevant choice is between a poorly enforced SMB income tax and a somewhat-better enforced gross receipts tax.

\section{Modified Gross Receipts (MGR) Tax: Using Historical Line-of-} Business Profit Ratios to Estimate Net Income.

\section{a. The Basic Idea}

If the regular income tax concentrates too much on achieving accuracy in the measurement of SMB income while sacrificing too much in terms of ease of enforcement (thus resulting in the current large SMB tax gap and a failure to measure income accurately in any event), and if a pure gross receipts tax is unacceptably inaccurate (producing the inefficiencies and distributive inequities described above), perhaps the best approach might be a compromise between the two. Specifically, consider a tax regime that requires each SMB taxpayer to report her gross receipts for the year just as under the present income tax, but that disallows all business expense deductions and instead imposes presumed profit percentages based on historical average profit ratios within the taxpayer's line of business. ${ }^{99}$ These presumed profit ratios could be either set by Congress or perhaps promulgated by the Treasury Department (under authority delegated from Congress) and would be based on their study of actual historical profit margins for particular industries and lines of business within industries (based on TCMP-type audits of a random sample of SMBs in each industry). ${ }^{100}$

These industry-specific presumed profit ratios could be made fixed or variable. If they were fixed, they would presumably be based on the best available evidence of actual industry profit margins at the time the regime was adopted. If they were variable, although they would start off based on the industry profit margins at the time of adoption, they would periodically be updated to reflect more current data, either

${ }^{98}$ Appendix A includes an example illustrating this difference between a gross receipts tax and either an income or a consumption tax, both of which are, in their ideal forms (including full enforcement and compliance) neutral with respect to the level of vertical integration. There is also an example explaining the cross-border inefficiencies associated with a gross receipts tax.

${ }^{99}$ Brazil uses an optional system along these lines to tax SMBs, as we explain below.

100 This is similar to what is already done under the Comparable Profit Method (CPM) for transfer pricing adjustments. Under the CPM, the IRS relies on the Standard Industrial Classification, published by the U.S. Department of Commerce, which classifies all businesses into categories. For all companies within a category, the IRS takes the tax returns data and calculates the profit margins, arranging them in a continuum from 0 to $100 \%$ (from least to most profitable), thus creating a bell-curve distribution. The area between the 25th and 75th percentiles of this curve is considered “arm's length" (or presumptively valid) under the CPM method. See Reuven S. Avi-Yonah, InTERnational TAX As InTERnational Law: An ANAlysis of The InT’L TAX Regime 215 (2007). 
through the regulatory process or through direct negotiations with representatives of the various industry groups. The advantage of using the fixed profit ratios is that the available evidence on actual profit margins is likely to be most accurate at the creation of the program. This is because, with the adoption of a presumptive regime, many SMB taxpayers might decide not to keep records of their expenses since they would no longer be allowed to deduct their business costs for tax purposes. ${ }^{101}$ In contrast, the advantage of variable profit ratios is that actual profit margins within various lines of business could change over time; and if such changes could be taken into account, the divergence between the presumptive income tax base and the actual income tax base would be reduced.

The actual details of an MGR presumptive regime are beyond the scope of this Article. However, for the sake of discussion we will work through a simple illustration. Start by imagining a regular income tax regime that imposes a 35\% levy on all business profits, and assume further that policymakers have decided to impose roughly that level of taxation on SMB profits as well. Now suppose that, because of the difficulty of policing an SMB income tax, policymakers adopt an MGR presumptive tax regime that has, say, five different SMB business categories, each with a different presumed profit percentage. For example, all SMBs might be grouped into $2 \%, 10 \%, 20 \%, 30 \%$, and $80 \%$ profit-percentage categories, again based on past profit experience tweaked for future expectations. Under this regime, then, if a business in the 30\% presumed-profit category earned $\$ 100$ of gross receipts during the year it would owe $\$ 10.50$ (.3 x .35 x 100) in federal SMB presumptive income tax. All SMBs would be grouped into one category or another based entirely on the historical profit experience for that type of business. How many separate line-of-business presumed profit classes should there be? How specifically and narrowly should they be drawn? These are difficult questions that raise precisely the sorts of tradeoffs between accuracy and simplicity that we discussed above. The more profit-percentage classes there are, the more accurate the approximation to actual income will be, but also the more complex and costly the regime would be to administer. Moreover, not only would it be difficult for the tax administrator to enforce a system with many lines of business, but

101 This concern would be somewhat mitigated if the particular presumptive regime that is adopted is made elective by taxpayers on a year-to-year basis, as discussed in the text below. If an SMB taxpayer knew that it would be allowed each year to choose between the presumptive and the regular business income tax, it would have an incentive to keep track of its business expenses. Also, it might be possible to incentivize SMBs to keep track of their expenses and to make those records available for government audits. For example, most SMBs will have non-tax incentives to keep expense records, and if (a) SMBs that get audited are paid a subsidy to compensate them for the cost and inconvenience and (b) they are also guaranteed that the data gathered from the audit will not be used to against them (except insofar as they contribute to the general pool of data that might affect the overall presumed profit margins), the resulting incentives might be sufficient to produce reliable updated data on industry-group profit margins. Alternatively, if the regime were set up so that the presumed profit ratios could be adjusted over time, presumably such adjustments would come through the normal notice-and-comment rulemaking process. This process would allow input from the representatives of various industry groups who wish to make the case (and present the evidence) that their group's profit ratio has declined, which should be reflected in the presumed profit for that line of business. There would obviously be a natural asymmetry in such a process, as few line-of-business reps would argue that their business has enjoyed increased profit margins and thus should be subject to higher progressive rates. But this bias in the process is not different in kind from the sort of bias that is built into many notice-and-comment rule-making situations. 
also it would be difficult for the taxpayer to self-assess which line of business she falls into. Our aim here is not to resolve the tradeoff but to highlight it. ${ }^{102}$

Because the MGR regime would be a compromise between an income tax and a gross receipts tax, it would have some of the same advantages and disadvantages of each of those regimes. There would be some but not all of the allocative inefficiency and distributive unfairness associated with a gross receipts tax. ${ }^{103}$ Thus, because an MGR tax would (by definition) be a function of gross receipts, there would, as with a pure gross-receipts tax, be a tax-based incentive for SMBs to minimize costs even in situations in which doing so would not necessarily maximize pre-tax profits; and there would be an incentive to avoid high-cost but high-profit industries. These effects, however, would be smaller than in the case of a pure, gross receipts tax. ${ }^{104}$ And the more fine-tuned the line-of-business presumed profit ratios are, the closer the regime would approximate an actual income tax, and the smaller these inefficiencies would be. Of course, the more fine-tuning there is, the greater the administrative cost of the regime, and hence the weaker the justification for moving away from current income tax system for SMBs.

One advantage of such a line-of-business presumed-profit approach to taxing SMBs over the current individualized actual-profit approach would be the reduced administrative or enforcement costs, which (ironically) could translate into greater accuracy and therefore improved distributional consequences. Under a line-ofbusiness presumed-profit tax, there would be no need for the government to monitor SMB taxpayers' individualized expenses. As a result, it would be relatively easy (i.e., relatively cheap) for the government to enforce remittance of SMB tax liabilities. The only information that the IRS would need in order to verify a taxpayer's tax liability would be the taxpayer's gross receipts for the year and its designated line-of-business. If we combine such a tax with an expanded regime of federal withholding (including payments to independent contractors and small corporations as well as wage payments to employees) and other means of third party reporting (such as credit card payments), it is possible that such a tax on SMBs could be a significant improvement over the current regime - that is, it could present a significantly lower MCF. Indeed, if the presumed profits under such a regime were even roughly correlated with most SMB taxpayers' actual profits, then the actual taxes remitted, and the accompanying distribution of the tax burden, could end up being much closer to the distributive ideal than is the case under the current individualized (and largely cheated) income tax regime. ${ }^{105}$

${ }^{102}$ Note that the IRS organizes all business-related income into 20 or so categories, including agriculture, construction, manufacturing, transportation, arts and entertainment, professional services, "other services," and so on. The object would be to group these together according to historical profit percentages, and to combine them into fewer categories.

${ }^{103}$ See Appendix A for the cascading effects of the MGR presumptive tax, when compared to taxes on gross receipts, income and consumption.

${ }_{104}$ Moreover, high-cost but high-profit ventures are not usually undertaken by small businesses. With the possible exception of high-tech start-ups that can attract venture capital investment, such investments usually require the sort of access to large amounts of capital that only big corporations (and certainly not SMBs) can manage.

105 The other significant advantage of a MGR presumptive tax regime is the potential savings in compliance costs. Again, under a MGR tax, SMB taxpayers would not have to justify their business expenses for tax purposes; as a result, they would not have to maintain all of the documentation required to substantiate their expenses, at least not at the level required under current U.S. income tax law. The 
Whether such a regime would actually work and be an improvement over the current system is a question that would turn on, among other things, the accuracy and variability of the IRS estimates of mean profit ratios. The more accurate the estimated mean profit ratios for particular lines of business and the less variable the estimates (i.e., the smaller the standard deviation around the mean), the more closely the regime would approximate the actual income-tax ideal. At the extreme, for example, if the historical mean profit ratio for a given line of business were $10 \%$, and the standard deviation within that profit-ratio class were literally zero, there would be essentially no difference between the presumed-income, MGR approach and the regular income tax, except that the former would be much cheaper to enforce. In that case, presumed profits for everyone in that line of business would equal actual profits. Such accuracy, of course, would not be achieved. There would inevitably some variation within the profit-ratio classes and the greater the standard deviation within the profit-ratio classes, the greater the inaccuracy of income measurement. ${ }^{106}$ The interesting questions then would be how narrowly these profit-ratio, line-of-business categories can be drawn and at what cost.

\section{b. Enforcement Concerns (and Potential Solutions)}

Even if an MGR regime could be designed with relatively narrow and accurate profit-ratio classes, such a regime obviously would not eliminate all SMB compliance concerns. For one thing, the problem of understated gross receipts would remain for certain classes of taxpayers - most obviously, businesses that provide goods or services directly to consumers. For those transactions, compulsory payer withholding and information reporting would simply not be feasible, for essentially the same reasons that it does not work to enforce the income tax against the self-employed: there are just too many of them, and they are too small to be worth going after en masse. Indeed, this is precisely why state governments that use retail sales taxes always place the primary remittance and information-reporting responsibilities on retail sellers rather than buyers; the compliance and administrative costs of the alternative remittance burden would be prohibitive. ${ }^{107}$ Thus, it should not be surprising that all of the proposals to expand compulsory federal withholding to include payments to ICs have been limited to payments made by business clients. ${ }^{108}$ Still, at least for those independent contractors, self-employed individuals, and small corporate businesses

resulting savings could be significant. The downside of these compliance-cost savings, again, is that over time there would be less taxpayer-specific information regarding actual SMB profit margins. This could be a problem if, in the future, tax policymakers wanted to update the presumed profit ratios.

${ }^{106}$ If, for example, the standard deviation within a given profit-ratio class were, say, 4 percentage points (and we assume a normal distribution), it would mean that roughly 32\% of the taxpayers within that profit-ratio class have profits for the year that were either below $6 \%$ or above $14 \%$. That degree of profit variability within a given presumed profit-ratio class would produce the same types of efficiency and distributional consequences discussed above in connection with a pure gross receipts tax. It would be to a lesser degree, however, since (again assuming a normal distribution) roughly $68 \%$ of the taxpayers within that $10 \%$ presumed-profit-ratio class would have profits between $6 \%$ and $14 \%$ - which of course is within 4 percentage points of the mean. That does not measure income with perfect accuracy, but it may come closer than we currently see with the income taxation of SMB taxpayers as a class.

107 Although placing the remittance burden on the retail sellers instead of on consumers makes enforcement of a retail sales tax viable, it is still the case that a VAT, with remittance obligations at every level of production, is generally thought to be the more easily enforced type of consumption tax.

${ }^{108}$ Likewise, when other countries have expanded withholding to include payments to the self employed, they have limited the withholding requirements to business payers. See generally Soos, supra note 12 . 
who receive a significant portion of their payments from business-client payers, expanded compulsory withholding and reporting requirements would be a relatively cheap and simple solution to the problem of understated gross receipts.

For those pesky business-to-consumer transactions, something other than expanded compulsory withholding will have to be tried. As mentioned above, insofar as those transactions involve credit-card or debit-card receipts where third-party monitoring can be employed, the problem is somewhat mitigated. ${ }^{109}$ We have already mentioned that credit-card and debit-card receipts are subject to third-party monitoring, which enables the IRS to determine if such receipts have gone unreported by SMBs. ${ }^{110}$ In addition, credit-card reporting may be a useful method of estimating cash income. If the IRS were able to determine an average ratio of cash to card receipts (this ratio could be tweaked by types of business, size, region etc.), it could trigger audits on SMBs that do not report cash receipts in an adequate proportion to their (already known by the IRS) card receipts. ${ }^{111}$ Also, money deposited in (or that flows through) financial institutions leaves a paper trail that could be used to trigger audits by the IRS. Many SMB taxpayers intent on tax evasion, of course, will be careful not to put their unreported cash receipts in the bank. Rather, they will spend this money on direct payments to certain suppliers or to employees who have a preference for receiving cash payments. ${ }^{112}$ Thus, other solutions to the problem of cash receipts will need to be tried. $^{113}$

${ }^{109}$ See supra note 18.

110 Indeed, the Morse, Karlinsky \& Bankman article suggests that most SMBs already report these transactions out of fear of getting caught. See Morse, Karlinsky \& Bankman, supra note 12.

111 Id.

112 Id. Informal payments and personal consumption might not be able to absorb all the concealed tax receipts, leading some taxpayer to acquire durable consumption assets like boats, cars and housing, or to adopt otherwise lavish consumption standards, such as traveling, hotels, etc. If this is the case, audits based on lifestyle-standards may be a good way to target the taxpayers that underreport receipts. A presumptive tax may also be based on these standards as we will see below, but keeping them as a guideline for auditing, instead of transforming them into an element of the tax base seems more sensible.

113 One jurisdiction in Brazil is experimenting with a way to harness both the power of the internet and the self-interest of consumers to help the taxing authorities monitor cash transactions between consumers and businesses. The program is designed to help with the implementation of the Brazilian State VAT in the State of São Paulo, but it could be adapted to aid enforcement of a presumptive SMB tax just as well. It works as follows: when an individual (or a legal entity) makes a purchase that is subject to the tax, the purchaser asks the seller to record the purchaser's taxpayer identification number and give the purchaser the invoice with the seller's taxpayer identification number. The purchaser can then file a form with the government to receive a credit or cash rebate from the state equal to some percentage of the tax that is paid. This way, if the seller has not paid the tax and recorded the transaction with the government, the purchaser will not get the rebate. To make sure that the seller records the purchase and pays the tax, the government has set up an internet site where the purchaser can go to see if the seller has complied. The beauty of the system is, if the individual has made a purchase and it does not appear on the website, she can report directly to the government that the purchase has occurred. The report can then trigger an audit on the noncompliant seller. The overall effect is that purchasers are induced to ask for the relevant documentation from sellers and sellers, competing for business, are induced to provide that documentation; and the overall enforcement of the tax system is improved. Again, this program is used in Brazil for VAT enforcement, but it could be used in the United States to tighten the control over the reported gross receipts of SMBs. If such a program is to work, however, a number of inherent problems would have to be overcome. For example, in the Brazilian experience, many consumers have been reluctant to participate because of the fear that the government might somehow use the information against them rather than against the noncompliant sellers. Brazil is taking a number of steps to overcome this concern, including 
In addition to the issue of under-stated gross receipts just discussed, the MGR presumptive income tax would also be subject to other types of evasion and avoidance. For example, SMBs could evade by simply disguising their high-profit businesses as low-profit ones. That is, if an SMB's tax liability under the presumptive system depends on its line of business, there would obviously be an incentive to manipulate (or simply to lie about) one's line-of-business designation. Determining whether a taxpayer has assessed her line of business correctly would require some amount of auditing, which would contribute to the administrative costs that the MGR tax is intended to reduce. These costs can be reduced by minimizing the number of lines of business; however, as mentioned, this solution would also reduce the system's fairness. One relatively cheap means of line-of-business auditing would be to cross-reference taxpayers' line-of-business tax designations with their business designations for other purposes. For example, if a taxpayer registers as a lawyer with the bar association, it will be difficult for that same taxpayer to self-designate with the tax system as anything other than a lawyer.

Besides the problem of taxpayers blatantly mischaracterizing their SMB's line of business, there is also the more pedestrian but no less thorny issues of line-drawing in marginal cases. For example, it is safe to assume that an MGR presumptive tax system would presume a higher profit ratio for service providers than for merchandise sellers/producers. But what about an SMB that straddles this line? Imagine an SMB construction contractor who provides both labor and materials for her construction projects. Which category should she fall into? The correct answer, of course, would depend on the relation between the cost of the inputs and the value of the service rendered, but we cannot draw the line based on costs, because the whole point of the MGR presumptive system is to ignore the role of expenses in determining the tax base. Thus, some objective line must be drawn, and some inequities will necessarily emerge. And of course taxpayers will exercise whatever discretion the rules give them to push these margins in their favor.

Finally, in addition to the problems of outright evasion and borderline cases, it is inevitable that sophisticated taxpayers would find ways to use an MGR system to engage in tax-planning or tax-sheltering activity. For example, non-SMB businesses that are taxed under the regular business income tax but that conduct more than one type of business activity would be tempted to restructure their operations into several smaller businesses, at least one or more of which could be taxed under the relatively low rates of the presumptive tax. Moreover, such restructuring would provide taxpayers with the opportunity to engage what amounts to a type of transfer-pricing manipulation under which income is shifting from one business, which is taxed under the normal income tax, to another business, which is taxed under the relatively low presumptive rates.

To see this last point, imagine a business that initially produces and delivers merchandise to its customers and is taxed under the regular income tax of $40 \%$. Let's say this business has receipts of $\$ 1,000$, production costs of $\$ 400$ (for raw material, labor, machinery depreciation, and the like), and transportation costs of $\$ 200$ (also for labor and other assorted costs). Thus, the pre-tax profit for the business would be $\$ 400$, which would be taxable under the normal income tax. Given an income tax rate

corrective advertising campaigns, but these remedial measures (and the program itself) are still too young to be definitively evaluated. 
of $40 \%$, the final tax liability would be $\$ 160$, and the after-tax profit would be $\$ 240$. Now let's say the production and transportation businesses are separated into two different businesses (owned by the same people) and the transportation business qualifies as an SMB while the production business remains under the regular income tax. Assume further that under the MGR presumptive tax system, transportation SMBs are taxed at a $40 \%$ rate on a presumed profit of $32 \%$ of gross receipts. In this case, the transportation SMB would have the same $\$ 200$ costs as before, but imagine that it would charge the production business $\$ 400$ for the transportation services that it provides. Thus, the transportation SMB's pre-tax profit would be $\$ 200$ : $\$ 400$ of receipts from the production company less the $\$ 200$ of expenses. The income tax would then be levied on the transportation company's presumptive profit, calculated by applying 32\% over the receipts of $\$ 400$. Thus, the income tax due by the transportation SMB would be $\$ 51.20$ (i.e. $40 \% * 32 \% * \$ 400$ ). Its after-tax profits would be $\$ 148.80$. The production business, however, would still have the same $\$ 1,000$ in gross receipts, but would now have costs of $\$ 800$ ( $\$ 400$ from production and $\$ 400$ from transportation). Its pre-tax profit would be $\$ 200$ on which the $40 \%$ income tax would be levied. The tax due would be $\$ 80$ and the after-tax profit of the production business would be $\$ 120$. Adding the transportation SMB and the production business's after-tax profits together, we would end up with $\$ 268.80$ of after-tax profits. This means that the separation of the two businesses and the shifting of some of the profits to the low-rate presumptive tax generated an extra $\$ 28.80$ in after-tax profits overall.

These are only a few of the numerous ways in which even moderately clever taxpayers would try to exploit the existence of two parallel systems of taxing business income. What this means is that the IRS would have to respond in some way by applying section 482 or the economic substance doctrine or some other anti-avoidance rules. And these responses will add complexity to the system, which in turn will add the administrative costs of the regime.

\section{Taxing Asset Values}

An alternative presumptive tax base would be wealth. More specifically, treat some percentage of a SMBs' net asset values as presumptive income. This idea has some merit. Indeed, some developing countries do just that, using asset taxes to supplement, or substitute for, the income tax on SMBs. And it is an idea that should not be dismissed out of hand for SMBs in this country.

Many of the issues that would need to be addressed here - i.e., the difficulty involved in the valuation of the assets, the fact that the tax is regressive, and so on have been discussed in the literature on wealth taxes or property taxes generally. ${ }^{114}$ The upside of such a tax is that asset values correlate with ability to pay, in some ways better even than income does. Also, reported asset values are not contingent on reported business expense deductions, which is one of the problems with the income tax. Nor would an asset tax require regular estimates of industry or line-of-business profit ratios, which is a problem with modified gross receipts tax. Perhaps the most

114 Other specific issues (e.g., integration, foreign tax credit and taxation of financial activities) would have to be addressed if one was dealing with a presumptive assets tax as a substitute (or minimum) for the corporate tax. See Thuronyi, supra note 73; Efraim Sadka \& Vito Tanzi, A Tax on Gross Assets of Enterprises as a Form of Presumptive Taxation (INT'L MONETARY FUND, Working Paper No. 92/16, 1992) for discussions on the fundamental aspects of this presumptive tax. 
important advantage of using asset values in the context of SMBs is that it would respond to the problem of consumer-to-business payments, which even the MGR approach (with compulsory withholding) cannot fully address. Arguably, it would be easier for the IRS to identify the taxpayers' assets than to monitor all of her cash gross receipts. It is harder to hide land, buildings, and other property. Also, these items are often already being taxed by the state authorities, and the federal government could conceivably piggyback on the state's enforcement regime. Again, some developing countries already do this.

The main problem with using an asset tax for SMBs, though, is that many SMBs have few tangible assets. Indeed, the type of businesses for which this type of evasion is most likely (the non-farm sole proprietors), the primary asset is the skill of the sole proprietor/entrepreneur, an asset that is notoriously difficult to value for the purpose of taxation. This is why the international experience shows that presumptive assets taxes are typically used to address problems other than the SMB tax gap. ${ }^{115}$

\section{Taxing Multiple-Factors}

Another presumptive tax base of sorts would be to use a multitude of factors that tend to correlate with income. The best example of such a regime, or the one that gets the most attention in the tax literature, is the Israeli tachshiv (or, as it is sometimes called, the Standard Assessments Guide). This method of taxing income was introduced in 1954, and, although formally ended legislatively in 1975, was used for several years after that by the Israeli taxing authorities as an informal guide to taxing self-employed taxpayers. ${ }^{116}$ Under the tachshiv, the taxation of SMBs was based on a sometimes long list of readily identifiable characteristics. Included among these characteristics, for example, was the type of business the taxpayer is operating, and not just whether it is a restaurant or a flower shop (although the restaurant/flower-shop distinction was one that mattered) but also the restaurant's hours of operation, how many waiters it employs, where the building is located, what type of food the restaurant serves, and so on. And there were similarly detailed breakdowns for lots of other types of businesses. All of these factors had been determined to correlate with varying levels of net income and thus were used by the taxing authority to generate a presumed amount of income for each very narrowly defined type of business. And that amount was taxed. ${ }^{117}$

115 As reported by Thuronyi, supra note 73, presumptive assets taxes have been adopted by Argentina, Colombia, Mexico, and Venezuela. These taxes, in effect, operate as alternative minimum taxes. Additionally, Bolivia experimented with replacing its corporate income tax with a presumptive asset tax. In all of these cases, the presumptive tax was not designed to deal with the SMB tax gap problem, but to serve as a general means of taxation of corporations or individuals. See also Sadka \& Tanzi, supra note 114 (explaining why developing countries adopted presumptive assets taxes as a minimum tax or as a substitute for the corporate tax); Sijbren Cnossen \& Lans Bovenberg, Fundamental Tax Reform in The Netherlands (Ctr. for Econ. Studies \& Inst. for Econ. Research, Working Paper No. 342, 2000) (commenting on the Dutch presumptive capital income tax, which substitutes for a tax on capital gains and is levied at a $30 \%$ rate on a $4 \%$ presumptive rate of return on individuals' assets).

${ }^{116}$ Yitzhaki, Cost Benefit Analysis, supra note 74, at 316. A version of it was also used by Spain and Turkey as well. Thuronyi, supra note 73, at 23 n.65 (citing Arye Lapidoth, The Israeli Experience of Using the Tachshiv for Estimating the Taxable Income, 31 BULL. FOR INT'L FISCAL Doc. 99 (1977)).

117 Actually, the tachshiv was never a mandatory exclusive tax, but rather an optional presumptive tax - or alternative presumptive SMB maximum tax. See infra. 
Something like this approach could be useful for the taxation of SMBs that sell directly to consumers, especially those that do business mostly in cash. The obvious disadvantage of the multiple-factor approach to presumptive taxation is the complexity and high costs of administration. In addition, there would be unfairness and inefficiency if, say, a restaurant of particular type, size, location, number of employees, and such happens to have unusually high business expenses and thus low profits in a given year. ${ }^{118}$ But this is the sort of problem that would face any presumptive tax regime.

\section{Of Mandatory Minimums, Optional Presumptive Regimes, and Other} Variations

To this point in the analysis we have assumed that the presumptive regime would be mandatory and exclusive, in the following sense: if a business qualifies as an SMB (for example, its gross receipts fall below the SMB threshold), then that business taxpayer must pay the presumptive tax liability. Thus, not only is the regime compulsory, but it is also exclusive in that the presumptive tax liability represents both the taxpayer's maximum and its minimum federal tax liability. As we have pointed out, such a mandatory-exclusive presumptive regime would entail certain advantages, such as reduced administrative and enforcement costs, but also would come with certain distributional and efficiency disadvantages. It is possible that these disadvantages could be reduced if the presumptive regime were made either optional or, if mandatory, non-exclusive. As we shall see, however, such changes would bring problems of their own.

\section{Mandatory Minimum}

A mandatory presumptive tax need not be exclusive. The AMT, for example, is a mandatory tax, but it is only a mandatory minimum. Under the AMT, a taxpayer must calculate both her AMT tax liability (called her "tentative minimum tax") and her regular income tax liability and then must pay the higher of the two. A mandatory minimum presumptive SMB tax would presumably work the same way. ${ }^{119}$ Thus, a qualifying SMB would have to calculate both its presumptive tax liability and its regular, income-tax liability and pay whichever is greater.

What would be the benefits of such an alternative to the mandatory exclusive regime discussed above? For one thing, the mandatory minimum version would be somewhat less regressive than the mandatory exclusive version. SMBs whose incomes turn out to be high enough to generate a regular income tax liability in excess of the amount owed on the presumptive amount would face whatever degree of progressivity is built into the income tax regime. For those SMBs who end up paying only the

118 The system would also be inefficient because it would serve as a negative stimulus towards some expenses and/or investments that are used as tags for the presumptive system, even though such expenses/investments would be profit maximizing in a non-tax world. For example, if the number of tables in a restaurant is decisive for taxation, the taxpayer might decide to use fewer tables because the additional tax burden would exceed the additional profit derived from the extra tables, although in a non-tax world, or even in a regular income tax world, the additional table would be a profit-maximizing decision. See Yitzhaki, Cost Benefit Analysis, supra note 74, at 321.

119 This name would be a bit misleading, however. While the current AMT is a sort of presumptive tax, it is not a presumptive tax that is directed at the problem of noncompliance. Rather, the AMT responds to a different type of problem: taxpayers combining a number of (entirely legal) deductions, exclusions, and credits to reduce their regular tax liability to zero - or at least to a very low number. The SMB presumptive tax (or Alt-SMB Tax) would be all about dealing with noncompliance, mostly evasion. 
presumptive tax, however, there would only be the degree of progressivity built into the presumptive regime, whatever that happens to be. Thus, with a lump-sum presumptive tax, for those who pay the presumptive tax, there would be no progressivity; with the MRG presumptive tax, there would be some progressivity; and so on. From an efficiency perspective, the results would again be mixed. If we consider only the taxpayers who pay the minimum presumptive amount, the results would be the same as under the exclusive presumptive system, which again would depend on which presumptive base was used. For those taxpayers who end up having to pay the regular income tax, the efficiency concerns would be the same as those presented by an income tax. The one difference might be additional pressure of a potential "cliff effect" for taxpayers whose income levels are close to the regular tax threshold; that is, if an SMB's regular income tax liability would be significantly higher than its presumptive tax liability, the work/leisure distortion may be especially large at the regular-tax/presumptive-tax threshold.

The big downside of the mandatory minimum presumptive SMB tax is that it does not significantly reduce administrative/enforcement costs associated with policing the SMB income tax after the income threshold is surpassed. That is, high-income SMBs would still have an incentive to overstate deductions or understate gross receipts in order to avoid paying the income tax. The presence of the mandatory minimum SMB tax would limit this incentive but would not eliminate it. The effect might be that most SMBs would end up paying the presumptive tax: low-income SMBs would pay because it would exceed their income tax liability; and many high-income SMBs (those willing to understate their actual tax liability) would end up paying it by default. And only the honest (or well socialized) high-income SMBs would pay the regular income tax. What's more, the government would not be able to prevent this sort race to the bottom from happening unless it could drastically improve its ability to enforce the income tax. But if we could do that cheaply, we would not need the SMB presumptive tax in the first place.

\section{The Ex-Post, Optional Presumptive Tax}

If policymakers find the distributional and efficiency concerns associated with a mandatory presumptive tax unacceptable, there is always the optional or elective approach. Consider for example an optional presumptive tax regime that allows a taxpayer to make the choice - whether to opt into the presumptive tax regime or whether to pay the regular income tax liability - at the end of the taxable year. Under such an "ex-post, optional regime," it is obvious that the taxpayer would choose the system that produced the lower tax liability. ${ }^{120}$ Thus, an ex-post, optional presumptive system would be a sort of alternative maximum tax: taxpayers would never pay more than the presumptive tax, but might pay less if their regular income tax liability proved to be lower.

One thing this would mean, of course, is that less revenue would be collected under an elective regime than under a mandatory presumptive regime that employs the same rate structure. To see this, return to our hypothetical tax regime that taxes business profits at $35 \%$ and that has five presumed-profit business classes for SMBs ranging from $2 \%$ to $80 \%$. Now assume that a particular line of business falls into the $30 \%$ presumed-profit category. If the MGR regime were mandatory, all SMB

120 This regime is comparable to the current standard deduction in the United States. See discussion, supra note 82. 
taxpayers in that line of business would expect to pay a presumptive tax of $\$ 10.50$ on every $\$ 100$ of gross receipts earned (30\% of 35\%). If 1000 such SMBs each earned $\$ 100$ of gross receipts for the year, $\$ 10,500$ would be collected in presumptive tax from the group. Of course, the actual profit percentages within this line of business would vary, with $30 \%$ perhaps being the mean. As a result, there would be some inaccuracy and unfairness owing to the cross-subsidization within the line-of-business presumptive tax pool, with the degree of cross-subsidization depending on the standard deviation of actual profit percentages within a group. This is just a restatement of the inherent inaccuracy of any presumptive regime that relies on presumed profit ratios.

If, however, the regime were made optional, those taxpayers whose actual profits for the year were less than $30 \%$ would do better to opt for the income tax, and those whose actual profits were greater than $30 \%$ should opt for the presumptive tax. Obviously, assuming at least some variation in actual profits within the line of business (as would obviously be the case), less than $\$ 10,500$ would be collected from the group in this example. And so it would be with an actual optional presumptive tax. How much the revenue from the group would drop below the amount collected under the mandatory presumptive tax would depend on the amount of the variation in profits within the group: the larger the profitability variance within the presumptive pool of SMB taxpayers, the larger would be the degree of inaccuracy and distributive unfairness inherent in a mandatory regime. By the same token, greater profit variance within the group would also mean a larger loss of revenue (in comparison with the mandatory exclusive regime) if the regime is instead made optional. ${ }^{121}$

A similar sort of story could be told about other presumptive tax bases. The same basic point would hold true: relatively high income taxpayers (those who would pay more under the income tax) would opt into the presumptive tax; and relatively low-income taxpayers (those with a lower profit margin than their proxy indicia would suggest) would opt for the income tax in order to pay the lower amount. If policymakers had a particular target level of revenue in mind, then they would have to make up the lost revenue resulting from making the presumptive tax optional from some other source, perhaps by raising rates on all income. So long as they raise rates on both actual income and presumptive income, however, the rate increase should not exacerbate the revenue loss.

It should also be clear that, if the presumed profit margins set by the government were to be adjusted periodically to reflect changes in actual line-ofbusiness profit margins, such adjustments should not be based on which SMBs opt into the presumptive regime and which do not. If that were done, it would cause a sort of line-of-business, profit-margin "unraveling" akin to what can happen with insurance pools. That is, with an insurance pool, where premiums are set at the average expected costs of the pool, individuals with higher than average expected costs will tend to opt into the insurance pool and individuals with lower-than-average expected cost will opt

${ }^{121}$ Of course, the actual loss of revenue that an optional presumptive tax would produce when compared with a mandatory exclusive presumptive tax would depend on how close the presumptive profit margins were to the mean within a given line of business. If the presumptive margins are set at the actual mean profit percentage within a line of business, then the degree of variance within that line of business around the mean will be directly related to the loss of revenue on the optional system. However, if the presumptive profit margin were for some reason set below the actual mean profit margin, some variance might not be enough to cause a loss. 
out. ${ }^{122}$ And because the premium is based on average risks, the premium will rise as adverse selection occurs; and the spiral can continue, as opting out of the pool becomes attractive for more insureds, until at some point either only very high-cost individuals are willing to buy the insurance, or the market entirely unravels. What would prevent this unraveling from occurring with the use of presumed profit margins based on industry means is that the presumed margins would either be fixed (based on the margins at the time the regime is adopted) or they would be updated periodically based on industry-wide data - and not on who opts into or out of the system. As we mentioned above (and discuss in further detail below), the best system for updating presumed profit margins would likely involve negotiations between the IRS and industry representatives.

An ex-post, optional presumptive tax would also be especially vulnerable to noncompliant taxpayers, those not burdened by conscience or fear of informal sanctions when it comes to gaming the tax system. The above-described self-selection process, where the high-profit businesses opt into the presumptive regime and the lowprofit businesses op out, would occur even if we assume everyone is seeking to comply fully with the tax laws. In addition, those relatively high-profit SMBs who are most willing and able to engage in noncompliance would have an extra incentive to opt into the regular income tax regime, where they can use their comparative advantage to exploit the enforcement difficulties associated with the net income taxation of SMBs. This incentive would cut in the opposite direction of the incentives facing the compliant, high-income SMBs, who would, again, tend to opt for the presumptive tax. And assuming that SMB noncompliance under the income tax is difficult to police, we would again see the same sort of inequity that we see today between the tax burden imposed on the compliant and that imposed on the noncompliant. Although at least under an optional regime, the high-income, compliant taxpayer would get to pay the lower of her income tax liability or her presumptive tax liability.

The problem of the noncompliant, high-income SMBs opting for the regular income tax under an optional presumptive tax might be dealt with by adopting separate penalties for the presumptive tax and the regular income tax. That is, we might imagine a penalty regime that says, if you opt into the presumptive tax regime, assuming you do not fraudulently hide gross receipts or lie about your line of business and assuming you do not engage in any clearly illegal presumptive-tax-shelter activity (described above), you will face a relatively favorable and friendly enforcement environment, one that will also be relatively cheap for the IRS to administer. ${ }^{123}$ If, however, you are an SMB that opts to be taxed under the regular income tax, you will face a more aggressive enforcement environment, with a higher probability of audit and a more searching and intrusive audit if you get audited. Also, if you happen to be found guilty of any sort of noncompliance, you would face a very stiff penalty. ${ }^{124}$ Of

122 This phenomenon, known as adverse selection, arises because of information asymmetry: whereas the insurer can observe only the average expected cost of the pool, individuals are assumed to know if their expected costs are higher or lower than average.

${ }^{123}$ This does not mean, however, that the probability of getting caught under this system is lower than under the regular system. The whole idea is to make the presumptive system easy and cheap to administer, and with a high probability of detection (thus, with no need for high penalties or costly audits).

124 This idea has much in common with Alex Raskolnikov's proposal for tailoring enforcement regimes to the type of taxpayer in question. Alex Raskolnikov, supra note 71, at 689. Raskolnikov's idea is to structure the tax enforcement regime so that it distinguishes between taxpayers who are "gamers" (the ones who are the classic rational actors of standard deterrence theory) and those who are not gamers, who 
course, the enhanced enforcement under the income tax for SMBs would be expensive (as we have said all along), but perhaps enough money could be saved from the lower enforcement costs on the presumptive tax side to fund the increase on the regular income tax side. One difficulty with this suggestion is that it would be hard for policymakers to calibrate the distinctions between the two enforcement regimes such that the appropriate incentives would be created. For example, if the enforcement environment of the presumptive tax regime were made too friendly and cooperative, it might be subject to exploitation - so much so, in fact, that high-profit taxpayers bent on noncompliance would actually do better by opting into the presumptive regime. The more likely outcome, however, is that some of the high-income noncompliers (or gamers) would opt into the presumptive regime, not to exploit the enhanced opportunity to engage in noncompliance but, to the contrary, to avoid the enhanced penalties in the other regime and, simply, to pay the lower tax. And if this happens, it would produce further administrative cost savings that could also be used to fund the increased enforcement efforts under the regular SMB income tax.

In sum, under the dual-track enforcement regime, two optional and parallel systems of SMB taxation would be created. The first one would be the presumptive system, which would be by its nature difficult to game (because of the compulsory withholding and the disallowance of all deductions) and in which high levels of compliance could be achieved even in an environment with low audit costs per taxpayer. The second system would be the regular income tax, which would be structurally easier to game (overstating deductions would still be possible) and where high level compliance could only be reached with either very high penalties or high audit costs per taxpayer. The larger the number of taxpayers that opt into the presumptive system, the higher the amount of resources that would be freed to enforce the regular system, leading to a higher overall compliance environment.

Having said all of this, what is the benefit of making the presumptive tax $e x-$ post optional in the first place? The answer is that by doing so we reduce a particular type of inequity: that of taxing the lower-than-average-profit business as if it were an average-profit business. Hence, the taxpayer who happens to incur larger expenses in a given year than others in the same line of business (under the MGR tax) or others with the same multi-factor profile (under the tachshiv-like tax) can opt for the more accurate and fine-grained calculation of income under the regular income tax. This would be an especially useful option for start-up firms, which almost always will have lower-thanaverage profits in their early years of operation. ${ }^{125}$ The reduction of this horizontal inequity is what makes the optional approach so appealing. There is also some enhanced efficiency associated with this approach, if only because, by lowering the overall tax burden (because of the option to pay the lower tax) we reduce the potential work/leisure distortion and the tax-induced incentive towards vertical integration. Whether the optional approach makes overall sense, then (compared with, say, the

want to pay their taxes out of a sense of duty or out of habit and have no interest in trying to exploit loopholes or play the audit lottery. Those who are in the former group would elect to be subject to what Raskolnikov calls the "traditional enforcement regime," with high penalties, high risk of audits, and the like. Those who are in the latter group would face a more cooperative enforcement environment.

${ }^{125}$ In fact, given this characteristic of start ups, it would make sense, even under a mandatory presumptive tax regime, to make the regime optional for start-up companies for the first several years of their existence. How many years they should get the regular income tax option would be determined by the Service and could vary across lines of business. 
mandatory version of the same tax), would depend on an analysis of whether the particular horizontal equity improvement described above, plus the slight efficiency improvement, would outweigh the various costs identified above, including the loss of revenue. ${ }^{126}$

\section{Variations on the Theme}

The Ex-Ante, Optional Presumptive Tax. Would anything change if the election to be taxed under the presumptive tax or the regular income tax had to be exercised ex ante (at the beginning of the year or at the beginning of some period of time, before the taxpayer's income is known) rather than ex post (after the taxpayer knows her income) ${ }^{127}$ In such a case (assuming, of course, that the option cannot be changed during the year), the taxpayer would not base her decision on a comparison of known tax liabilities, but rather on an educated guess as to what her future income may be. Still, the analysis would be much the same: taxpayers who expect to have a relatively high income would opt into the presumptive system and taxpayers expecting a relatively low income would opt out. And for those who guess correctly, the analysis of the inequities and inefficiencies would be the same as under the ex-post, optional regime. For those who guess wrong, however, the outcome is mixed. For those who wrongly opt into the presumptive system - i.e., they thought that their tax liability under the regular system would be higher than the presumptive amount, but it ended up being lower - the ex-ante, optional system is more regressive than the ex-post one, though no more regressive than the mandatory approach. For those taxpayers who wrongly opt for the regular system (expecting to have a relatively low income but in fact experiencing a relatively high income), the ex-ante system is more progressive than the ex-post, optional system, and indeed more progressive than the mandatory presumptive regime. That is, the taxpayer essentially would be opting to be taxed under the higher-income, tax regime. ${ }^{128}$

Negotiated approach. Rather than imposing a presumptive tax from the top down, with Congress and the IRS imposing a given set of rules, it might be better (and more feasible) to imagine a greater degree of cooperation between the regulators and the regulatees in this case. In some countries that use presumptive taxes, this approach is taken to the extreme in the following sense: taxpayers are actually allowed to enter into contractually binding agreements with the taxing authority about what their tax liability will be. France, for example, has done this since the 1960s under a system known as the forfait, which has been applied to as many as a million individual taxpayers in a given year. ${ }^{129}$ A forfait-type regime would almost certainly not be administratively feasible for the U.S. tax system, given the large number of SMBs involved. Still, for some types of presumptive tax regimes, it might be possible to allow large groups of SMBs collectively to negotiate some aspect of the presumptive tax with the IRS. Imagine, for example, an MGR presumptive income tax under which SMBs that work within the same line of business could, as a group and through group

${ }^{126}$ The tachshiv, when it was still on the books, was an ex-post optional presumptive regime. Now it is an audit strategy with commitment.

${ }^{127}$ The Brazilian regime is an ex-ante optional MGR presumptive regime.

${ }^{128}$ As with the distributional effect, the efficiency effect of taxing people on their ex-ante guess about their ex-post profit situation is also mixed, depending on the direction of the mistakes.

${ }^{129}$ See Thuronyi, supra note 73. The tachshiv also had some features that representatives from each economic sector could negotiate with the Tax Agency. See Arachi \& Santoro, supra note 40, at 230. 
representatives, negotiate the presumptive profit margins for their line of business with the IRS. This process, which would be similar to the notice-and-comment rulemaking that already exists, would stimulate SMBs to keep track of their business expenses in order to show the IRS, in a negotiation, what the average profit margin of their group actually is. If such an approach worked properly, it would make possible regular updating of the MGR presumed profit margins. Moreover, such a system would reduce the possibility of taxpayers' lying to the IRS about their line of business (in order to be taxed under a lower MGR margin), because the SMBs themselves would police who would be allowed into their group (in order to avoid outsiders having a say with respect to the reported margins). Thus, even though individual contracts between individual SMBs and the IRS are a nonstarter to solve the SMB tax gap problem, other types of collectively negotiated outcomes may in fact work.

The Presumptive Tax Idea as Audit Strategy. The IRS might also consider using one or another presumptive tax regime as an audit tool for enforcing the existing regular income tax rather than as an actual separate presumptive tax system. Under such an enforcement approach, the regular income tax would continue to be the only tax system that would apply to SMB taxpayers, but the Service would use some presumptive tax formula (one like the MGR or the multi-factor presumptive tax discussed above) to calculate the taxpayers' hypothetical presumptive tax liability. ${ }^{130}$

Under one version of this audit-strategy approach, the Service would (a) tell taxpayers how to calculate their hypothetical presumptive tax liability and (b) credibly commit to audit only those taxpayers who declare income that falls below the hypothetical presumptive amount. The result would be similar to that under the $e x-$ post, optional presumptive tax system discussed above. Relatively high-profit SMBs (those with high enough profits to generate a tax liability under the regular income tax that is greater than their presumed tax liability) would report only the presumed amount on their income tax return: any less would trigger an audit: any more would subject them to unnecessary taxation, given the administration's credible commitment not to audit them if they report at least the presumptive amount. On the other hand, SMBs with a tax liability below the presumed amount (at least the ones willing to be noncompliant with the statutory law given that tax authority's stated audit policy) would declare their actual income and expect to be audited, which would be the equivalent of opting out of the presumptive system as discussed above.

The import of this analysis is that the tax enforcement authority (the IRS) could, by announcing and credibly committing to this sort of presumptive-tax type of audit strategy, roughly approximate the result that could otherwise be achieved only with the legislative adoption of a new optional presumptive tax regime. We say "roughly approximate" because at least some honest taxpayers would see a difference between the presumptive tax audit strategy and the statutory optional presumptive tax regime. That is, these honest (pathologically compliant) high-income taxpayers would be more than happy to opt into a statutorily-provided presumptive regime and forego paying the higher-income, tax liability but would be very reluctant to respond to an announced presumptive-tax, audit policy by gaming the system and declaring less tax than they actually owe under the statute.

${ }^{130}$ The Israeli system currently uses the tachshiv as a sort of audit strategy. Arachi \& Santoro, supra note 40, at 230. See also Thuronyi, supra note 73. 
If such an approach were to be followed, these new audits of SMBs who report income below the presumptive amount would be administratively costly. If enough SMBs declare at least the presumed amount (which, as already discussed is inherently cheaper to enforce), however, then audit resources would be freed up and could be redirected towards those who declare income below the presumptive level. ${ }^{131}$ Moreover, as with the optional presumptive tax, there could be an enhanced penalty for the regular income tax system. Given the fact that the taxpayers that pay the presumptive amount are under an audit "safe harbor," a simple increase in penalties for SMBs would hit only those that declare amounts lower than the presumptive one, i.e., those that are still under the regular income tax system. Of course, an increase in formal penalties for noncompliance would probably have to be enacted by Congress.

The previous example assumed that the IRS could credibly commit to its audit policy. But what if it couldn't? In that case, the results might be very different. For example, if the IRS publicized its presumptive tax audit strategy and taxpayers initially believed them, then taxpayers willing to be noncompliant would do so. That is, the relatively high-income taxpayers would declare the presumptive amount though, under the statute, they owe more. The problem is that the IRS, anticipating this behavior by taxpayers and being unable to pre-commit, would then find it impossible to resist auditing some fraction of the ones who declared the presumptive amount. Of course, once the IRS discovered some taxpayers who were noncompliant, it would want to stick them for the additional tax and penalties. Assuming taxpayers are rational, of course, they will see this bait-and-switch coming; and the high-income gamers, knowing that the IRS could not credibly commit to its stated audit policy (or could not be trusted to follow it), would ex ante decide not to declare the presumptive amount or at least their incentive to do so would be diminished. And the whole point of the audit-policy would be defeated. ${ }^{132}$

There is also a third possibility. What would happen if the IRS used a presumptive audit strategy without the taxpayers' knowledge of it? This would be another version of the discriminant index function (DIF) currently used by the IRS (or a mere addition of data and variables to the DIF), but specifically targeted at SMBs. If taxpayers are (and remain) unaware of the audit strategy used by the IRS, they will keep reporting income as under the current system. However, it is possible that several "gamers" who nowadays get away with evasion will start being audited under the new strategy. If that is the case, SMBs will perceive a higher enforcement rate and may start evading less. However, it is also possible that over the years (after sequential "games"), taxpayers (and preparers) realize the formula used by the IRS to select the returns that will be audited. If that happens, taxpayers might start declaring not more than the presumptive amount and a result similar to the audit policy with commitment would be reached. To avoid this outcome (if, in fact, keeping the presumptive method a secret is more efficient than making it public and credibly committing to it), the IRS should make constant updates to the presumptive system and avoid giving away their audit strategy.

131 This is a version of the optimal audit policy with commitment, as portrayed by Arachi \& Santoro, supra note 40, at 229. The authors describe the Italian Study di Settore as an audit strategy with commitment and reach similar conclusions as the ones described above. Id. at 237.

${ }^{132}$ Michael J. Graetz, Jennifer F. Reinganum \& Louis L. Wilde, The Tax Compliance Game: Toward an Interactive Theory of Law Enforcement, 2 J. L. ECON. \& ORG. 1 (1986). 


\section{CONCLUSIONS AND CAVEATS}

\section{A. General Remarks}

The aim of this Article has been to highlight the primary tax enforcement problem in the United States, that of noncompliant small and medium-sized businesses ("SMBs"), and to explore the possibility of a radical solution: shifting away from the current system that attempts to tax the actual individualized income of those businesses and toward a system that taxes only a very rough approximation of business income. This sort of presumptive tax approach has been used for years in developing economies, where the problem of SMB noncompliance is even worse. Our argument is that the time may have come for taxing SMBs in the United States on a presumptive basis as well.

But we do not go quite so far as to advocate such a change. As we set out in some detail above, such a shift would amount to a massive tradeoff of accuracy of income measurement for lowered costs of tax enforcement, and more research is needed on both sides of that question. How much of a loss of accuracy would result from the various presumptive-tax regimes discussed above? What would be the enforcement-cost savings? The particular regime that we spend the most time developing is a type of modified gross receipts tax, which would tax SMBs on a rough estimate of their annual income using their reported receipts and historical line-ofbusiness profit percentages, coupled with mandatory withholding requirements. There, the key questions would be: how narrowly and accurately can such line-of-business profit percentages be drawn and at what cost? If the answers are very narrowly, very accurately, and very cheaply, then an argument could be made for replacing the income tax for SMBs with a mandatory modified gross receipts tax. If, however, the line-ofbusiness, profit-percentages exhibit considerable variability, then making such a regime optional becomes much more appealing because it would reduce (though not eliminate) the unfairness associated with cross-subsidization within the profitpercentage groups. Also, if an optional presumptive regime were adopted, serious consideration should be given to imposing a dual-track enforcement regime, under which naturally compliant (non-gaming) taxpayers would be enticed into the presumptive tax system, thereby saving administrative dollars that could be spent on enforcing the income tax against those taxpayers more willing to engage in noncompliance.

The changes just described would require a major reform of the Internal Revenue Code. As a more modest alternative that might be able to achieve some of the same results, it might also be worth considering having the IRS begin to use presumptive-tax principles as part of their audit strategies. If the Service could credibly commit to applying some form of presumptive tax system in its auditing decisions (as part of the Discriminate Index Function, say), and if taxpayers reacted rationally to such an audit policy, the results could be similar to an optional presumptive business income tax. Such an approach, however, would have at least two significant problems. First, it would be difficult for the Service to make such a commitment credible. Second, even if such an approach worked to perfection (the Service was able to precommit and taxpayers responded rationally), the way in which such a regime would "work" would be to induce those taxpayers willing to understate their taxes (the gamers or cheaters) to pay only the presumptive amount while the non- 
gaming taxpayers with the same level of income would pay the higher income tax liability.

Many other questions remain as well. For example, what should be done about noncompliant, SMB taxpayers who do not receive most of their payments from other businesses (but rather receive payments mostly from individual consumers), and thus for whom compulsory withholding would not be practical. In this Article we have suggested some possible ideas, such as the expanded use of third-party reporting, like financial institutions that administer credit and debit-card purchases. (Not only are such transactions easier to monitor than cash transactions, they can also be used to estimate the amount of cash being received by businesses). In addition, there are various innovative solutions that might be tried, such as the Brazilian experiment with consumer-based monitoring and reporting of SMB tax compliance using the Internet, although most such experiments are still too young to be definitively evaluated. At the end of the day, for those SMBs that tend to do a large fraction of their business in cash, something like the Israeli-style, multi-factor approach may be necessary, at least as part of the IRS's auditing strategy.

Moreover, even if one were persuaded that some sort of new tax enforcement initiative for noncompliant SMBs (whether shifting to a presumptive tax or simply raising penalties or having more audits) might make sense in the abstract, it could be argued that now is not the time. Small businesses are the primary producers of new jobs in the economy, the argument would go, and the current tax system, under which SMBs are essentially allowed to "get away with" substantial noncompliance, amounts to a type of implicit federal tax subsidy for job-creating SMBs. ${ }^{133}$ And this is a good thing. Any of the presumptive-tax solutions discussed above, therefore, would undercut that subsidy and further harm the economy. Our response to this type of argument is twofold. First, it is actually far from clear that small businesses provide any more job creation (net of "job destruction") than do larger businesses. At least not so much that they should be singled out for a special subsidy. ${ }^{134}$ Second, even if one disagrees with that conclusion and believes it necessary and appropriate to subsidize small businesses, there are much better (more efficient, more distributively sensible and transparent) ways of subsidizing small businesses than by essentially giving money to the ones that are in industries (or in forms of organization) that find it easiest to evade taxation and those most willing to ignore the law and social norms of legal compliance.

\section{A. VAT as an alternative}

There is one critique of our proposal that deserves a separate and sustained response. One could argue that if we are willing to enact a change in the law as radical as the introduction of a presumptive system of income taxation, it would make more sense simply to enact a value added tax (or VAT), a change that has been discussed

${ }^{133}$ Indeed, Morse, Karlinsky, and Bankman found that many SMB taxpayers who engaged in evasion were of the view that the IRS's underenforcement in this area was "sound government policy" and equivalent to a small-business subsidy, similar to (and justified in the same way as) direct subsidies to farmers and other industries). See Morse, Karlinsky \& Bankman, supra note 12, at 67. Some of the interviewees also expressed the view that, if the IRS were to require full tax compliance among SMBs, many of them would be forced out of business. Id.

134 See Steven J. Davis, John C. Haltiwanger \& Scott Schuh, Job Creation And DESTRUCTION 57-75 (1997). 
and advocated by some in the United States for quite some time. It is beyond the scope of this Article to discuss all of the pros and cons of the migration from an income-tax regime to a consumption-type tax such as the VAT. However, we should say something about the ability of the VAT, in comparison with a presumptive tax, to solve the problem of SMB tax noncompliance.

First, we need to clarify what we mean by a VAT and whether we mean for the VAT to replace or supplement the income tax. A VAT is very much like retail sales taxes, with one important difference: the tax is levied on (or remitted by) taxpayers at every step of the production/sales chain. To avoid a cascading effect of multiple taxes on the same good, each taxpayer within the chain of production is allowed a credit for the amount of VAT that has already been remitted by the previous taxpayers in the chain. The advantages of this difference from the retail sales tax, which calls for remittance only on the final retail sale, are twofold. From a fairness perspective, it allows for the VAT to be levied on the same overall base as the retail sales tax, i.e., the sale price to the consumer. ${ }^{135}$ From an enforcement perspective, the VAT is superior to the sales tax because it does not focus the remittance obligation exclusively on the retail sellers, which are often the hardest-to-enforce link of the chain. It rather spreads the liability and remittance obligation over all the steps of the chain, making the revenue impact of evasion by one particular taxpayer less relevant. Also, the creditnote method provides a useful third-party reporting enforcement tool: a taxpayer is only allowed to claim a VAT credit if she has documentation proving that the previous taxpayer on the production/sales chain has effectively remitted the VAT. This means that, at least to some extent, taxpayers will self-enforce the VAT upon each other and will provide the IRS with relevant cross-referenceable data on the receipts/expenses of one another.

That is the VAT. The next question, when comparing the VAT to the presumptive tax in addressing the SMB gap, is whether we have in mind a complete overhaul of the current income tax system, that is, an outright repeal of the existing income tax and the replacement of it with a VAT? Or are we talking about the enactment of a VAT as a new tax on top of the current income tax ${ }^{136}$ If it is the latter, then SMB income-tax noncompliance would continue to be an issue, simply because the income tax (and the income tax gap) would not cease to exist. Although one could argue that the VAT enforcement would bring positive externalities to the income tax enforcement, ${ }^{137}$ it is highly uncertain if such externalities would suffice to solve (or relevantly improve) the SMB income tax enforcement issues.

${ }^{135}$ If one adds all the VAT effectively remitted by each taxpayer over a certain production/sales chain - i.e., VAT liability minus VAT credits - the overall amount of VAT remitted is roughly the same as the amount of sales tax that would be remitted if only a sales tax at the same rate had been levied on the sale by the retailer. See Appendix A for more details on this. Of course, this assumes a VAT that allows for instant credit of capital goods (i.e., expensing), which would be the case with a VAT that seeks to tax only consumption. See Richard A. Musgrave \& Peggy B. Musgrave, Public Finance in Theory and PRACTICE 441-445 (4th ed. 1984).

${ }^{136}$ Graetz, Reinganum \& Wilde, supra note 132; Reuven S. Avi-Yonah, The Three Goals of Taxation, 60 TAX L. ReV 1 (2006); Reuven S. Avi-Yonah, Designing a Federal VAT: Summary and Recommendations (John M. Olin Ctr. for L. \& Econ., Working Paper No. 104, 2009).

${ }^{137}$ For example, we will see below that a credit-invoice based VAT would provide the IRS with extra third-party reporting, which could be used for income tax purposes, to check some of the taxpayer receipts and deductions. 
But what if the proposal were to replace the income tax entirely, along with whatever version of our presumptive income tax were to get adopted for SMB income, with a VAT? Then the question of which regime better deals with the SMB tax gap would depend heavily on comparative abilities of the presumptive regime and the VAT alternative to deal with the two general types of evasion: the overstatement of deductions and understatement of receipts. And this comparison will depend, in turn, on which type of presumptive tax we have in mind. As mentioned above, an MGR presumptive tax would deal with the overstatement of deductions by simply disallowing them and substituting instead a presumed profit based on some measure of average expenses within the relevant line of business. Moreover, by means of withholding and third party reporting, it would be able to deal with the understatement of SMB's receipts from other business or credit card receipts from consumers. As we have mentioned, the MGR presumptive tax would have no good answer to the problem of SMB evasion through the understatement of cash receipts.

Conversely, the VAT, when applied to SMBs, would need to deal with the problem of SMBs understating their receipts and overstating their expenses. On the expenses' side, we concede that there are reasons to believe that the problem of expense overstatements under the VAT is less severe than the problem of deduction overstatements under a standard income tax. First, there are fewer VAT creditable items than income-tax deductible expenses. (Under a VAT, deprecation is not deductible, for example; whereas, under an income tax it is). This simple fact means there are fewer opportunities to overstate expenses under the VAT. Second, VAT credits are only allowed for expenses in goods and services that have been taxed by the VAT. This means that one taxpayer's credit is matched with another taxpayer's VAT liability. Thus, if the IRS has a powerful enough data cross-reference system, overstated credits could ideally be caught on the spot, without the need for auditing. This means that the VAT is probably superior to the regular income tax in dealing with the expenses' (deductions/credits) overstatement problem. However, the VAT's system is not as effective as the disallowance of all deductions by the MGR presumptive tax, simply because no third party reporting mechanism beats the plain removal of the expenses from the equation.

On the receipts side, the VAT would also count on the credit-note method to provide sufficient self-enforcement and third party reporting that would undermine underreporting on transactions between taxpayers. ${ }^{138}$ Also, the VAT could rely on credit card companies' reporting to deal with business-to-consumer transactions. However, much like the MGR presumptive tax, the VAT would not be able to deal with business-to-consumer cash transactions. Other presumptive income taxes, such as multiple factor, assets, or lump-sum taxes discussed above might be superior to either the VAT or the MGR presumptive tax for dealing with cash transactions and overstated deductions, but would have fairness, efficiency, and even administrability issues of their own, as we have already analyzed earlier. ${ }^{139}$ In sum, the VAT would address some of the SMB tax gap issues addressed by presumptive taxes, but not all of such issues and probably not as well as the presumptive systems in some cases.

138 This would not deal, however, with the judgment-proof issue that income tax withholding would address.

${ }^{139}$ As mentioned in an earlier note, there might be some mechanisms that could deal with the underreporting of cash transactions, be it for income tax, sales tax or VAT purposes. 
If one is truly committed to moving towards a VAT, but is concerned about the problem of noncompliance among SMB taxpayers, there are other alternatives as well. For example, the VAT regime could simply exempt from taxation SMB taxpayers whose revenues fall below a certain threshold, or noncompliance by such taxpayers could simply be ignored. This approach has its own disadvantages, as we discussed above in connection with the idea of simply regarding SMB income tax noncompliance as a subsidy for SMBs. ${ }^{140}$ As an alternative, if one wanted to go with a VAT but did not want to exempt all SMB transactions, it would be possible to adopt a presumptive VAT. Under such a regime, the presumptive VAT would require taxpayers, in calculating their VAT remittance responsibility, to rely on some proxy for a business's expenses, rather than the actual expenses. And the idea would be for this proxy to be something that is substantially easier for the tax authorities to measure and, thus, enforce. Then this presumptive deductible amount would be credited to the next taxpayer in the chain of production. Such a regime would have much the same advantages and disadvantages of a presumptive income tax regime.

In any event, one should note that a VAT reform would be much more far reaching than the enactment of any presumptive SMB tax. While the presumptive tax reforms would not go beyond the SMB issues analyzed herein, a VAT reform would affect all taxpayers with major fairness, efficiency, and administrability consequences for all of them. ${ }^{141}$ Thus, although we focused above only on the VAT's ability to deal with SMB enforcement, this is just one (minor) point to consider in the debate of a VAT reform.

${ }^{140}$ However, there might be relevant incidence differences between the VAT and the income tax that would make a VAT SMB exemption very different from an income tax SMB exemption.

${ }^{141}$ These issues have already been reviewed in literature and fall out of the scope of this Article. 